\title{
¿Characteristics of Cold-Air Outbreak Events and Associated Polar Mesoscale Cyclogenesis over the North Atlantic Region
}

\author{
Annick Terpstra, ${ }^{\mathrm{a}, \mathrm{b}}$ IAN A. Renfrew, ${ }^{\mathrm{b}}$ AND Denis E. SergeEv ${ }^{\mathrm{c}}$

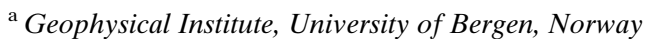 \\ ${ }^{\mathrm{b}}$ School of Environmental Sciences, University of East Anglia, Norwich, United Kingdom \\ ${ }^{\mathrm{c}}$ College of Engineering, Mathematics and Physical Sciences, University of Exeter, Exeter, United Kingdom
}

(Manuscript received 29 July 2020, in final form 8 February 2021)

\begin{abstract}
Equatorward excursions of cold polar air masses into ice-free regions, so-called cold-air outbreak (CAO) events, are frequently accompanied by the development of severe mesoscale weather features. Focusing on two key regions, the Labrador Sea and the Greenland-Norwegian Seas, we apply objective detection for both CAO events and polar mesoscale cyclones to outline the temporal evolution of CAO events and quantify associated mesoscale cyclogenesis. We introduce a novel metric, the CAO depth, which incorporates both the static stability and the temperature of the air mass. The large-scale atmospheric conditions during the onset of CAO events comprise a very cold upper-level trough over the $\mathrm{CAO}$ region and a surface cyclone downstream. As the CAO matures, the cold air mass extends southeastward, accompanied by lower static stability and enhanced surface fluxes. Despite the nearly $20^{\circ}$ difference in latitude, CAO events over both regions exhibit similar evolution and characteristics including surface fluxes and thermodynamic structure. About twothirds of the identified CAO events are accompanied by polar mesoscale cyclogenesis, with the majority of mesoscale cyclones originating inside the cold air masses. Neither the duration nor the maturity of the CAO event seems relevant for mesoscale cyclogenesis. Mesoscale cyclogenesis conditions during CAO events over the Labrador Sea are warmer, moister and exhibit stronger surface latent heat fluxes than their Norwegian Sea counterparts.
\end{abstract}

KEYWORDS: Atmosphere-ocean interaction; Cold air surges; Cyclogenesis/cyclolysis; Extreme events; Mesocyclones; Polar lows

\section{Introduction}

In the North Atlantic region heat, moisture, and momentum exchange between the ocean and atmosphere modulates the global oceanic heat transport (Buckley and Marshall 2016; Renfrew et al. 2019). Atmospheric forcing is the main driver for this local air-sea exchange and intermittent excursions of cold polar air masses over the open ocean, that is, maritime cold-air outbreak (CAO) events, account for $60 \%-80 \%$ of the wintertime ocean heat loss (Papritz and Spengler 2017). In addition, the effects of mesoscale phenomena, such as boundary layer fronts, orographically driven low-level jets, and polar mesoscale cyclones (PMCs), can significantly enhance oceanic heat transport (Pickart et al. 2003; Condron and Renfrew 2013; Jung et al. 2014). These mesoscale phenomena are frequently observed in conjunction with CAOs (e.g., Harold et al. 1999; Drüe and Heinemann 2001; Sergeev et al. 2017) emanating in a symbiotic forcing of the underlying ocean. The interaction and combined effect of CAOs and mesoscale phenomena has barely been examined and is a focus here.

To assess the interaction between CAOs and mesoscale phenomena, we will outline the characteristics of objectively identified CAO events over the North Atlantic region and their co-occurrence with PMCs. Our approach is to characterize $C A O$ events as opposed to the more commonly used gridpoint-

¿ Denotes content that is immediately available upon publication as open access.

Corresponding author: Annick Terpstra, annick.terpstra@uib.no based analysis of CAO conditions. This approach facilitates examining the temporal evolution of CAO events and quantifying associated PMC development. In addition, we introduce an alternative metric for CAOs, the CAO depth, which provides a different perspective on the spatial and temporal evolution of CAOs to the commonly used temperaturedifference-based CAO index.

Adopting a stationary-air-mass perspective on CAOs, Iwasaki et al. (2014) considered the low-level air mass bounded by the $280-\mathrm{K}$ isentrope as representative of cold polar air masses. They identified two key regions associated with a strong outflow of polar-air-mass fluxes in the Northern Hemisphere, both located over the source regions of the midlatitude storm tracks. Note, however, that on shorter time scales this cold-air outflow is nonstationary and alternates with poleward intrusions of warm, moist air. Indeed CAOs are a vital part of the meridional heat exchange between the midlatitudes and the polar regions, operating in tandem with warm intrusions [see Pithan et al. (2018) and references therein]. The meridional flow that dictates these fluctuations is driven by transient atmospheric features, with favorable conditions for maritime CAOs being in the rear of synoptic-scale cyclones (i.e., in the cold sector) (Kolstad et al. 2009; Fletcher et al. 2016a).

Maritime CAOs are atmospheric phenomena entailing equatorward excursions of cold polar air masses over the relatively warm adjacent open ocean. As a consequence, CAOs often result in extreme air-sea thermal differences contributing to large heat losses from the underlying ocean (Brümmer 1997; Renfrew and Moore 1999; Wacker et al. 2005). This effect of CAOs is frequently used to identify maritime CAO conditions. In fact, the bulk of CAO metrics (Kolstad et al. 2009; 
Kolstad 2011; Papritz et al. 2015; Fletcher et al. 2016a) are based on temperature differences between the surface and the atmosphere at some level, similar to the bulk formula used in models to calculate surface fluxes over the ocean. This favors the paradigm of CAOs being defined as vehicles for air-sea exchange, as opposed to excursions of polar air masses. Notice the distinction between these two perspectives. Using an "air mass" definition requires the air to be cold relative to some benchmark. Making that benchmark the sea surface temperature (SST) introduces a geographical condition that results in regions with climatologically higher SSTs appearing more prone to CAOs.

A focus on air-sea heat exchange is important for the highlatitude regions, where heat loss from the ocean modulates deep water formation rates. In the North Atlantic local maxima in surface sensible heat fluxes during the winter season are located in both the Fram Strait and the Labrador Sea near the ice edge (Moore et al. 2012). Both maxima can be attributed to CAOs (Papritz and Spengler 2017). From observations it is evident that the cold air during CAOs is modified by the underlying ocean, warming through upward surface sensible and latent heat fluxes and reducing the airsea temperature difference with fetch (Brümmer 1997; Renfrew and Moore 1999; Liu et al. 2006). This evolution affects both the air-sea temperature difference and the CAO temperature and structure, but will be seen differently for metrics based on the air mass or based on the air-sea temperature difference.

Polar mesoscale cyclones (PMCs) are small scale (diameter of several hundreds of kilometers), short-lived (lifetime between 9 and $36 \mathrm{~h}$ ) maritime cyclones developing poleward of the main baroclinic zone. Polar lows are a subset of PMCs consisting mostly of longer-lasting, more intense PMCs. Many polar lows, if not all, develop in the proximity of CAOs (see, e.g., Shapiro et al. 1987; Douglas et al. 1995; Pagowski and Moore 2001; Claud et al. 2004; Brümmer et al. 2009; Wagner et al. 2011; Sergeev et al. 2017). Several climatological studies have used this single-sided co-occurrence as motivation to use CAO metrics as a proxy for polar low development, and compiled climatologies of polar low potential (Kolstad 2006; Claud et al. 2007; Kolstad 2011; Landgren et al. 2019b). However, most of these studies fail to address whether CAO conditions are sufficient for polar low development, which raises questions as to whether climatological CAO changes are indicating PMC changes. Landgren et al. (2019a) found a decline in their CAO metric and a concerted decline in polar low occurrence, although it should be noted that their selection criteria for polar lows encompassed the same CAO metric. Michel et al. (2018) compared their objective PMC climatology, which included polar lows, with commonly used CAO metrics and point out that these CAO metrics are generally a poor predictor of PMC development. Thus, it remains unclear how suitable CAOs, and specifically CAO metrics, are as an indicator of PMC and/or polar low development.

By forcing an ocean-only model with parameterized heat and momentum exchange representative of PMCs, Condron and Renfrew (2013) showed that PMCs enhanced dense water formation and ocean heat transport in the subpolar seas. Along similar lines, Jung et al. (2014) forced an ocean-only model with wind fields at different horizontal resolutions and found that the higher resolution, which resolved more mesoscale features, resulted in $5 \%-10 \%$ increase in wind-driven gyres and the Atlantic meridional overturning circulation. Hence the integral effect of mesoscale atmospheric features appears to be to enhance the momentum forcing and heat loss from the ocean. However, some case studies have shown that interactions between CAOs and PMCs can potentially alleviate these impacts. Papritz and Pfahl (2016) found that latent heat release associated with several PMCs at the fringes of a CAO quickened the erosion of the CAO air mass and thereby indirectly reduced the $\mathrm{CAO}$ induced heat loss from the underlying ocean.

Thus, insight into the collocation of PMCs and CAOs is instrumental for assessing their combined effect on the underlying ocean. Here we investigate this by first examining how we define CAO conditions and CAO events (section 2), second by characterizing CAO events (section 3), and then third by quantifying PMC activity during CAO events (section 4), before concluding in section 5 .

\section{Data, definitions, and methods}

\section{a. Data}

We use ERA5 (Hersbach et al. 2020), the latest reanalysis product provided by the European Centre for Medium-Range Weather Forecasts (ECMWF), interpolated to a horizontal resolution of $0.25^{\circ}(\approx 28 \mathrm{~km})$ and with 3-hourly temporal resolution. We focus on the North Atlantic region and consider extended winter seasons, from November to March, from 2002 to 2018. The selected months cover the peak season for CAOs (Kolstad et al. 2009), polar mesoscale cyclones (Michel et al. 2018), and polar lows (Noer et al. 2011), while the 16-yr period has a sufficient number of events to establish robust characteristics. Given the rapid changes in high-latitude regions, for example the disappearance of the wintertime Oden ice tongue over the Greenland Sea (Moore et al. 2015), resorting to a recent period provides a dataset representing the current state of high-latitude North Atlantic winter conditions. ERA5 is a relatively new reanalysis product and so has not been extensively evaluated for its ability to represent CAOs, although a recent analysis of surface layer meteorology and fluxes over the Iceland and Greenland Seas demonstrates that ERA5 has generally low biases and is relatively accurate over open water when compared to buoy, research vessel, and aircraft observations (Renfrew et al. 2021). In addition, its predecessors have proven to be reliable and accurate in reproducing CAO conditions in the subpolar North Atlantic (e.g., Renfrew et al. 2009; Harden et al. 2011, 2015) and in detecting polar lows and PMCs within the constraints of their resolution (e.g., Condron et al. 2006; Laffineur et al. 2014; Zappa and Shaffrey 2014; Sergeev 2018).

\section{b. The cold-air outbreak index}

A CAO index is defined as follows:

$$
\text { CAO-index }{ }_{\text {plev }} \equiv \theta_{\text {skt }}-\theta_{\text {plev }}
$$

where "plev" indicates a pressure level, $\theta_{\text {plev }}$ the potential temperature at this pressure level, and $\theta_{\text {skt }}$ the surface skin potential temperature. This CAO metric is a proxy for the 
(a) frequency (\% of time); caoheight $<800 \mathrm{hPa}$, caoidx at $800 \mathrm{hPa}>0$

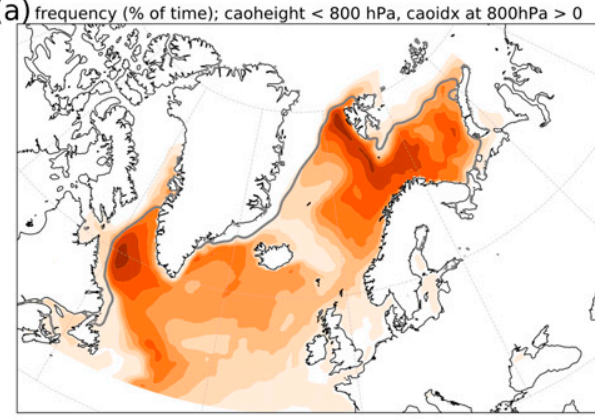

(c) wintermean (nov-mar, 2002-18) caoidx at 800hPa $>0$ [K]

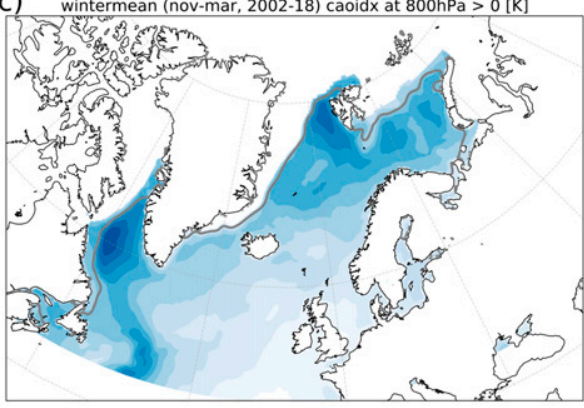

(b) wintermean (nov-mar, 2002-18) surface skin temperature $[\mathrm{K}]$

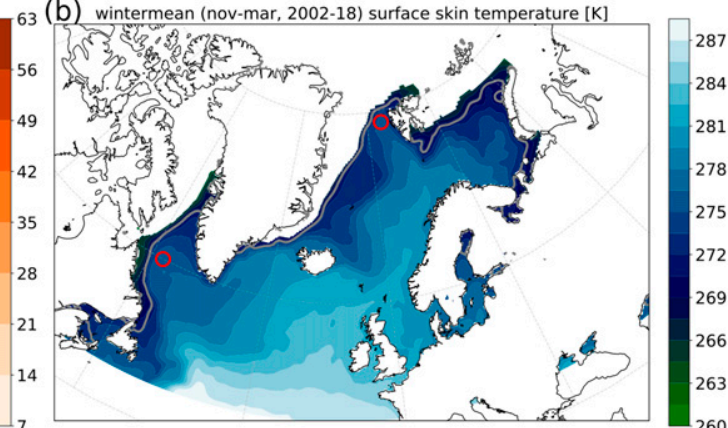

(d) wintermean (nov-mar, 2002-18) caoheight $<800$ [hPa]

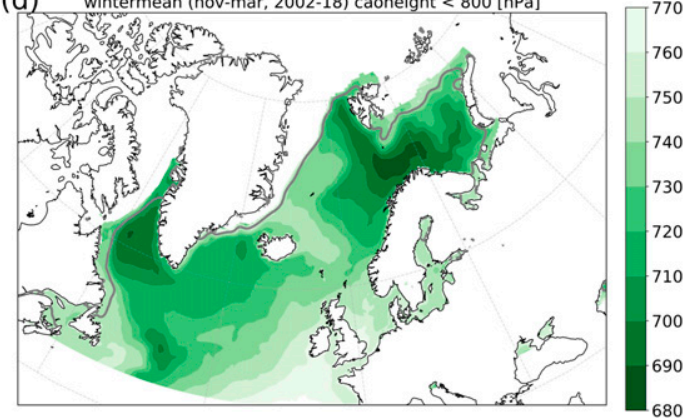

FIG. 1. (a) Winter-season (November-March 2002-18) occurrence of the CAO index at $800 \mathrm{hPa}>0$ and CAO height $<800 \mathrm{hPa}$ (shading; units: \% of time), and the winter-mean (b) surface skin temperature (shading; units: K), (c) $\mathrm{CAO}$ index at $800 \mathrm{hPa}$ only including positive values, i.e., $\mathrm{CAO}$-index $\mathrm{x}_{800}>0$ (shading; units: $\mathrm{K}$ ), and (d) CAO height, i.e., the height of the isentrope with a value equal to the surface skin temperature, only including CAO height $<800 \mathrm{hPa}$ (shading; units: hPa). Gray lines represent the winter-mean sea ice edge (defined as the sea ice fraction of 0.2). The rooting regions for identification of CAO events are indicated with red circles in (b).

sea-air temperature difference induced by CAOs. Numerous studies utilize this CAO metric, or variations of it, to associate atmospheric conditions over maritime regions with CAOs (e.g., Kolstad and Bracegirdle 2008; Kolstad et al. 2009; Papritz et al. 2015; Fletcher et al. 2016a,b; Kolstad 2017; Papritz and Sodemann 2018; Landgren et al. 2019a,b).

Figure 1a displays the distribution of the frequency of occurrence during the winter season for a positive CAO index at $800 \mathrm{hPa}$ (i.e., CAO-index $\mathrm{C}_{800}>0$ ). The spatial distribution exhibits a strong imprint of the sea surface temperature (Fig. 1b), with local peak frequencies in areas where cold polar air masses, originating from ice-covered regions, first encounter the relatively warm and ice-free ocean in the Labrador Sea and the Fram Strait. In contrast, the tongue of cold sea surface temperatures east of Greenland (including the extension northeast of Iceland) is characterized by low frequencies of CAO, despite this part of the Greenland Sea experiencing similar temperature anomalies at $800 \mathrm{hPa}$ to the Fram Strait area (not shown).

During winter the condition CAO-index $x_{800}>0$ is satisfied most of the time (frequency $>50 \%$ ) over the Labrador Sea and the Fram Strait region, with peak frequencies up to $70 \%$ and relatively high frequencies extending downstream. Increasing plev (i.e., evaluating the air closer to the surface) results in even higher frequencies of occurrence with similar spatial patterns (not shown). The spatial pattern of the frequency distribution resembles the distribution of Papritz and Spengler (2017), which is based on identification of air-parcel trajectories satisfying $\theta_{\mathrm{skt}}>\theta$ using ERA-Interim data. Here, using ERA5, we resolve some more detailed structures due to the higher spatial resolution. Absolute values for the frequencies of occurrence in their study are comparable or larger than for CAO-index ${ }_{800}>0$; differences can be attributed to their use of trajectories below $800 \mathrm{hPa}$. Thus, positive values of sea-air temperature difference are the primary condition in winter over the majority of the North Atlantic maritime region. Given that the condition $\theta_{\text {skt }}>\theta$ is more common than not over a large fraction of the North Atlantic, it is questionable whether these conditions should be categorized as CAOs-that is, " . . a vigorous equatorward thrust of cold polar air..." (AMS Glossary) over a relatively warm ocean-or whether they represent a general wintertime situation of relatively low air temperatures, and arguably labeling them simply as "cold air" (without the addition of "outbreak") is a more appropriate description.

A common method of distinguishing between these winter season conditions and more intense CAO conditions is to impose threshold values for the CAO index (Kolstad and Bracegirdle 2008; Kolstad et al. 2009; Papritz et al. 2015; Fletcher et al. 2016a,b; Kolstad 2017; Papritz and Spengler 2017; Papritz and Sodemann 2018). For example, Papritz and Spengler (2017) classify $25 \%$ of CAOs moderate, strong, or very strong using a CAO index $>4 \mathrm{~K}$ threshold. The winter mean amplitude of the CAO-index $\mathrm{x}_{800}>0$ provides a spatial 
blueprint for this selection method (Fig. 1c), illustrating that regions of higher winter mean values for $\mathrm{CAO}$-index 800 (i.e., regions favorable for high $\mathrm{CAO}$ index values) are located over the Labrador and the Fram Strait region and rapidly decrease with distance from the ice edge. This reflects the initially cold and unmodified air mass encountering the open ocean, after which the magnitude of the CAO index rapidly decreases with fetch, due to surface heat exchange with the underlying ocean and increasing SSTs. Thus, an artifact of this CAO metric is that imposing a threshold value on the CAO index favors identifying regions with warmer ocean temperatures adjacent to the ice edge as more intense CAO conditions.

\section{c. Identification of $C A O$ events}

Due to the relatively large differences in the SST adjacent to ice-covered areas the amplitude of the winter mean CAO-index $_{800}$ exhibits large spatial variability, which can be problematic when using a fixed threshold value to determine $\mathrm{CAO}$ conditions. To sidestep this artifact of the CAO index, we define a threshold for the CAO index with respect to local climatological conditions, thereby allowing for identification of CAO conditions even in regions with relatively low SSTs. Furthermore, to attribute PMCs to episodic CAOs, we focus on individual $C A O$ events as opposed to identifying $C A O$ conditions for a grid point.

We limit our analysis to the two most prominent CAO regions in the North Atlantic, the Labrador Sea and the Fram Strait region. For both regions, we define a $\mathrm{CAO}$ "rooting region" with a radius of $100 \mathrm{~km}$ centered at $60^{\circ} \mathrm{N}, 57^{\circ} \mathrm{W}$ (in the Labrador Sea) and $79^{\circ} \mathrm{N}, 6.5^{\circ} \mathrm{W}$ (in the Fram Strait); see circles in Fig. 1b. These rooting regions are located over the maxima in the winter-mean CAO index, both in amplitude and frequency. They are also roughly collocated with the local maxima in sensible heat flux during the winter and positioned over the ice-free ocean, adjacent to ice-covered regions (Moore et al. 2012). We focus on the characteristics of just two regions to allow a thorough investigation without excessive length; however, we have also examined CAO over the Iceland Sea and concluded that our analysis is broadly representative of other CAO regions.

Identification of the onset and termination of CAO events is based on time series of the area-averaged CAO-inde $x_{800}$ over the rooting regions, smoothed with a 2-day running mean. $\mathrm{CAO}$ events are designated when the $\mathrm{CAO}$-index $\mathrm{x}_{800}$ is greater than the $\theta$ threshold, where the $\theta$ threshold is the local winter mean plus one standard deviation of the CAO-index $x_{800}$ in the rooting region. For the Labrador Sea the applied $\theta$ threshold is $7.5 \mathrm{~K}$, while for the Fram Strait region the $\theta$ threshold is $6.3 \mathrm{~K}$. To eliminate transient events this condition has to be satisfied for a duration $>24 \mathrm{~h}$. Thus, we define CAO events with respect to local climatological values over a region with relatively uniform SST, so as to ensure the identification of intense and persistent events.

\section{d. The cold-air outbreak depth}

Associating PMCs with CAOs requires a measure for the spatial extent of the CAO air mass. Iwasaki et al. (2014) used an isentropic perspective and nominated the air below a fixed isentropic level as the CAO air mass, whereas Papritz and Spengler (2017) designate trajectories as belonging to the $\mathrm{CAO}$ air mass as long as their potential temperature is less than the surface skin potential temperature. Inspired by these approaches we define a novel metric, the height of the $C A O$ as the vertical level where the potential temperature equals the sea surface skin potential temperature (i.e., the CAO height is the pressure level where $\theta=\theta_{\text {skt }}$ ). Accordingly, the pressurethickness of the CAO air mass is defined as the CAO depth = $\mathrm{sfc}_{\text {plev }}-\mathrm{CAO}$ height, with $\mathrm{sfc}_{\text {plev }}$ being the pressure at sea level. Note that the CAO height is equivalent to CAOindex $_{\text {plev }}=0$, with "plev" being the CAO height. Thus, the frequency of occurrence is identical for CAO-index $x_{800}>0 \mathrm{~K}$ and CAO height $<800 \mathrm{hPa}$ (Fig. 1a).

The amplitude of the CAO height $<800 \mathrm{hPa}$ exhibits a rather different spatial distribution compared to the amplitude of the CAO-index ${ }_{800}>0$ (cf. Figs. $1 \mathrm{c}$ and 1d). For a CAO, as the fetch over the ocean increases, both the temperature and the depth of the neutrally stratified layer increase; consequently maxima in the CAO height are not necessarily confined to warm SSTs along the sea ice edge, but can also occur climatologically downstream. This is especially clear downstream (southeast) of the Fram Strait region over the Norwegian-Barents Sea, where there is a local maximum, but it is also evident in the Labrador Sea, where larger values of the CAO height extend into the Irminger Sea. Note that the spatial distributions of the frequency of occurrence of CAO conditions (Fig. 1a) are more like that of the CAO height (Fig. 1d) than of the CAO index (Fig. 1c).

Given the underlying SST, the CAO depth reflects the potential temperature and the static stability of the air mass, whereas the CAO index reflects the potential temperature at a single level. Following a CAO downstream, the cold air mass warms so the air-sea temperature difference decreases; and the $\mathrm{CAO}$ atmospheric boundary layer (ABL) height asymptotes toward a constant level with downstream distance (e.g., Chang and Braham 1991; Renfrew and King 2000). At some point, the sea-air temperature difference will cross the CAO index threshold and this marks the limit of the $\mathrm{CAO}$ by this metric. In contrast, the CAO depth represents an "integrated" measure. Consequently, the CAO depth metric is more directly related to the CAO air mass itself, but is perhaps more reliant on model parameterizations of $\mathrm{ABL}$ turbulence in determining the level where $\theta=\theta_{\text {skt }}$.

This difference is illustrated in Fig. 2, which displays the spatial distribution of the frequency of occurrence of CAOs for comparable CAO metric thresholds. Both chosen thresholds have a frequency range up to $20 \%$ and so capture "intense" CAO conditions (Papritz and Spengler 2017; Fletcher et al. 2016a). The spatial extent for the CAO index frequency metric is confined to warm SSTs next to the sea ice, whereas the extent the CAO height frequency metric covers the downstream development areas of the CAO air mass. The differences in spatial extent provided by the two metrics are relevant when considering for example the area-integrated air-sea exchange associated with CAO events, or the attribution of precipitation to CAOs (which has a tendency to increase downstream; Papritz and Sodemann 2018), or in this case identifying a 
(a) frequency (\% of time), caoidx at $800 \mathrm{hPa}>8[\mathrm{~K}]$

(b)

frequency (\% of time), caoheight $<650 \mathrm{hPa}$,
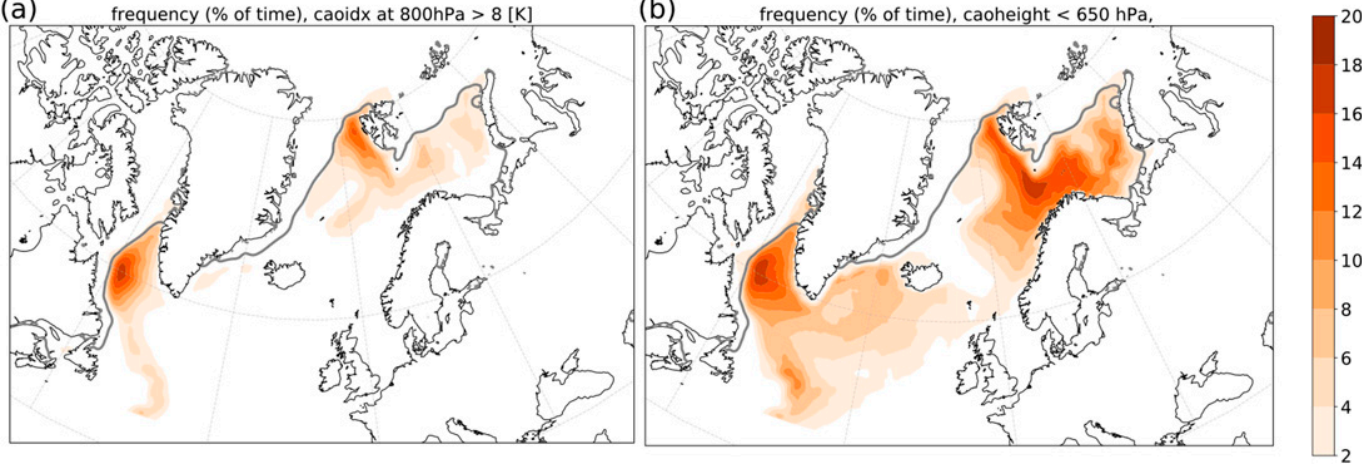

FIG. 2. Grid-point-based frequency of occurrence during the winter season (shading; units: \% of time) for (a) the $\mathrm{CAO}$ index at $800 \mathrm{hPa}>8 \mathrm{~K}$ and (b) $\mathrm{CAO}$ height $<650 \mathrm{hPa}$. The gray lines indicate the winter-mean sea ice edge.

coincidence of PMCs and CAOs, as PMCs do not necessarily develop at peak CAO-index 800 locations.

To further illustrate the relationship between and implications of using either metric, we consider the CAO-index ${ }_{800}$ and CAO height over the rooting region in the Labrador Sea (Fig. 3). Any CAO-index ${ }_{800}$ is associated with a range of CAO heights and vice versa; the upper and lower bounds of this range are limited by the lower-tropospheric stratification, which varies between moderate to strongly stratified over the rooting region. Imposing threshold values (exemplified by the thresholds used in Fig. 2, marked as solid lines in Fig. 3) indicates that besides the large overlap, there are CAO points that meet only one or the other of the CAO metric thresholds. The histogram of the CAO height is skewed with a relatively large tail to lower pressure values (i.e., higher altitude; gray histogram on the right in Fig. 3). In contrast, the histogram of the CAO index metric is more symmetric (i.e., closer to a normal distribution). We interpret this difference as the CAO height more readily capturing extreme $\mathrm{CAO}$ conditions and thus providing a better indication of extreme events than the CAO index. Negative values of the CAO index still correspond to a CAO height; that is, the pressure level for $\theta_{\text {skt }}$ is above the surface, where the stratification determines the magnitude and sign of the air-sea temperature difference.

The choices of both the pressure level and threshold for the CAO index impact the spatial distribution of CAO conditions by this metric. Imposing higher thresholds shifts the distribution toward the ice edge, whereas increasing the pressure level shifts the distribution toward regions with larger magnitudes of the CAO depth. For example, Kolstad et al. (2009) and Kolstad (2011) used the CAO-index $x_{700}$ and thus their climatology shows high frequency of occurrences over the Norwegian and Barents Sea, but lacks a peak over the Fram Strait due to their choice of plev $=700 \mathrm{hPa}$. In contrast, changing the CAO depth pressure threshold predominantly changes the frequency of occurrence rather than the distribution.

\section{e. Detecting polar mesoscale cyclones}

The identification of polar mesoscale cyclones (PMCs) is based on the cyclone detection and tracking algorithm of Watanabe et al. (2016). This algorithm has been designed specifically for tracking mesoscale cyclones and has been used successfully to compile PMC datasets in different regions, such as over the Japan Sea (Watanabe et al. 2016, 2017) and the Nordic seas (Sergeev 2018). Cyclone detection is based on determining local vorticity maxima at $900 \mathrm{hPa}$, while the tracking is performed by connecting the evolving vortices using first guesses from the ambient wind field. The algorithm uses several criteria to distinguish between synoptic-scale cyclones, mesoscale cyclones, and frontal structures [for details, see Watanabe et al. (2016)].

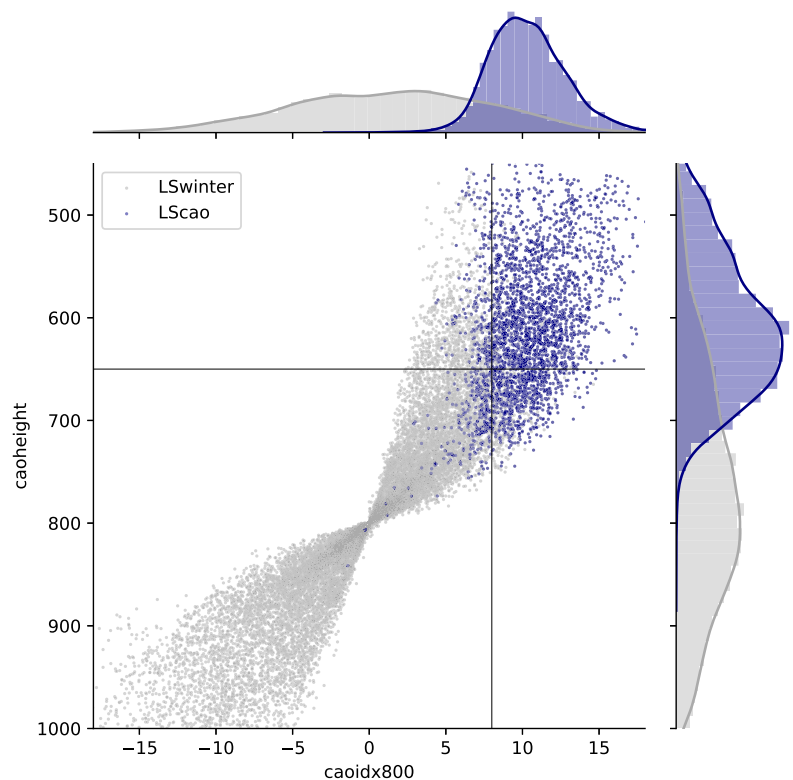

FIG. 3. Scatterplot of the instantaneous (3-hourly) CAO-index 800 (units: $\mathrm{K}$ ) vs CAO height (units: $\mathrm{hPa}$ ) during the winter-season (November-March 2002-18) area averaged over the Labrador Sea rooting region (see Fig. 1b), distinguishing between winter-season values (gray) and during CAO events (purple; CAO events as defined in section 2c). (top),(right) Normalized histograms (bars) and their corresponding kernel density estimation (solid line). The $\mathrm{CAO}$ height $=650 \mathrm{hPa}$ and $\mathrm{CAO}$-index $\mathrm{x}_{800}=8 \mathrm{~K}$ are marked in the scatterplot with horizontal and vertical lines, respectively. 


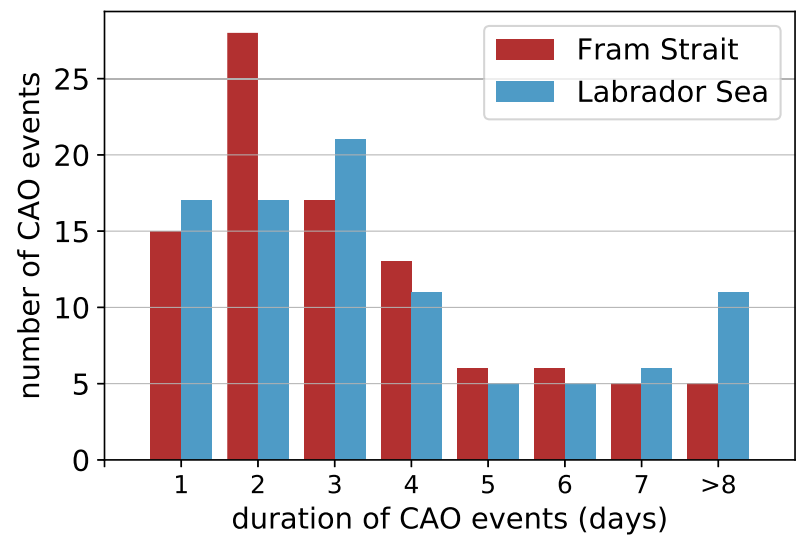

FIG. 4. Histogram of the duration of CAO events (units: days) for the Labrador Sea and the Fram Strait region.

In this study, mesoscale cyclones are filtered from the rest of the tracks using the following criteria: (i) maritime: genesis over the ice-free ocean (distance from land and/or sea ice $>$ $100 \mathrm{~km}$ ) and $>50 \%$ of lifetime over open water, (ii) mesoscale: $>80 \%$ of lifetime classified as "mesoscale cyclone" [for details, see Watanabe et al. (2016)], (iii) nonstationary: distance between genesis and lysis of at least $300 \mathrm{~km}$, and (iv) polar: genesis on the cold side of the main polar front (potential vorticity $>2$ PVU at $315 \mathrm{~K}$, for an area averaged over a radius of $200 \mathrm{~km} ; 1 \mathrm{PVU}=10^{-6} \mathrm{~K} \mathrm{~kg}^{-1} \mathrm{~m}^{2} \mathrm{~s}^{-1}$ ).

This yields a PMC dataset containing longer-lived maritime PMCs, including the strongest PMCs (polar lows), while excluding cyclones and frontal structures associated with the main storm track. Polar lows are a subset of winter season PMCs, and the tracking algorithm identifies matches for the majority of polar lows $(>80 \%)$ in satellite-based datasets when applied to ERA5 output over the Nordic seas region (Sergeev 2018).

\section{Cold-air outbreak events}

In total we identified 93 (95) CAO events in the Labrador Sea (Fram Strait) region over 16 extended-winter seasons or in other words $5.8 \pm 2.6(5.9 \pm 2.4) \mathrm{CAO}$ events (mean \pm one standard deviation) per season for each region. The median and the lower and upper quartiles of the duration of CAO events were 3.0, 1.9, and $4.8(2.5,1.8$, and 4.1$)$ days, respectively (see Fig. 4 and Table 1). The time scales for CAO events reflect synoptic-scale forcing; occasionally $\mathrm{CAO}$ events can last for more than a week, in either region, which is likely related to persistent large-scale atmospheric conditions, such as blocking. Papritz (2017) also defined CAO events over the Irminger Sea with respect to local climatological values, and found considerably more $\mathrm{CAO}$ events per season; however, he assigned events to individual peak values, so that during longer-lasting $\mathrm{CAO}$ conditions several events were counted when we would count just a single event.

\section{a. Characteristics of cold-air outbreak events over the rooting regions}

Atmospheric conditions during CAO events, as defined in section 2, represent persistent deviations from the local climatological mean of anomalously cold air in the lower troposphere. During the winter season CAO events occur $15 \% \pm 9 \%$ and $13 \% \pm 7 \%$ of the time over the Labrador Sea and Fram Strait region, respectively. In Fig. 5 we compare the atmospheric conditions during $\mathrm{CAO}$ events to those of the winter season for the two rooting regions (see Fig. 1b for locations), noting that atmospheric conditions during CAO events are a subset of the winter season conditions. In general, due to the choice of defining CAO events as anomalous conditions from the winter mean, the distributions of most variables are much narrower during $\mathrm{CAO}$ events than during the winter season. Interestingly, the distributions for the two regions are rather similar during the winter season, as well as during CAO events, which is remarkable given the nearly $20^{\circ}$ difference in latitude between the regions.

Not surprisingly, CAO events are characterized by cold and dry conditions, with the total column water vapor reducing to less than half the winter median and temperatures at $800 \mathrm{hPa}$ around $9 \mathrm{~K}$ lower during CAO events (Figs. 5a,b). CAO events over Fram Strait are only slightly colder and drier than over the Labrador Sea. The cold conditions in the lower troposphere

TABLE 1. Characteristics of cold-air outbreaks (CAOs) and polar mesoscale cyclones (PMCs) during winter (November-March 200218). Three selection criteria are used: CTL is the control configuration as described in section 2; nonMAR includes nonmaritime PMCs, so those with genesis over sea ice or orography; and proxCAO dispenses with the proximity restriction for PMCs being close to CAOs. The mean plus and minus one standard deviation are shown for CAO and PMCs per winter. The median and, in parentheses, the lower and upper percentiles are shown for CAO duration and PMCs per CAO event. Deviations from CTL are in boldface.

\begin{tabular}{|c|c|c|c|c|c|c|}
\hline & \multicolumn{3}{|c|}{ Labrador Sea } & \multicolumn{3}{|c|}{ Fram Strait } \\
\hline & CTL & nonMAR & proxCAO & CTL & nonMAR & proxCAO \\
\hline No. of CAO events (total) & 95 & 95 & 95 & 93 & 93 & 93 \\
\hline CAOs per winter & $5.8 \pm 2.6$ & $5.8 \pm 2.6$ & $5.8 \pm 2.6$ & $5.9 \pm 2.4$ & $5.9 \pm 2.4$ & $5.9 \pm 2.4$ \\
\hline CAO duration (days) & $3.0(1.9,4.8)$ & $3.0(1.9,4.8)$ & $3.0(1.9,4.8)$ & $2.5(1.8,4.1)$ & $2.5(1.8,4.1)$ & $2.5(1.8,4.1)$ \\
\hline PMCs total & 1654 & 2161 & 1654 & 1240 & 1823 & 1240 \\
\hline PMCs during CAOs & 235 & 334 & 275 & 167 & 244 & 214 \\
\hline PMCs per winter & $103 \pm 24$ & $135 \pm 28$ & $103 \pm 24$ & $77 \pm 12$ & $114 \pm 13$ & $77 \pm 12$ \\
\hline PMCs per winter during $\mathrm{CAO}$ & $15 \pm 13$ & $21 \pm 16$ & $17 \pm \mathbf{1 5}$ & $10 \pm 7$ & $15 \pm 10$ & $13 \pm 9$ \\
\hline PMCs per CAO event & $1(0,3)$ & $2(1,5)$ & $2(0,4)$ & $1(0,2.5)$ & $2(0,4)$ & $2(0,3)$ \\
\hline CAOs without PMCs (\%) & 30 & 24 & 29 & 37 & 27 & 29 \\
\hline
\end{tabular}


during CAO events are accompanied by a reduced tropospheric depth, as evident from the reduced potential temperatures at the dynamical tropopause (2 PVU; Fig. 5c).

In both regions the winter median $\mathrm{CAO}$-inde $\mathrm{x}_{800}$ is positive, and increases on average to about $10 \mathrm{~K}$ during $\mathrm{CAO}$ events (Fig. 5d). The CAO depth during CAO events is around $380 \mathrm{hPa}$, with occasionally very high $(>500 \mathrm{hPa})$ values during CAO events over the Labrador Sea (Fig. 5e). Related to the CAO depth is the boundary layer height, which is deeper over the Labrador Sea than the Fram Strait both during the winter season and during CAO events, with deeper boundary layers over both regions during $\mathrm{CAO}$ events due to the larger surface heat fluxes generating enhanced thermally driven mixing and pumping up the boundary layer (Fig. 5f). Note that a negative CAO-index ${ }_{800}$ does not necessarily imply downward surface sensible heat fluxes, as the near-surface air temperature, and thus the air-sea temperature difference, depends on the static stability of the atmosphere.

Indeed, during the winter season the surface sensible heat fluxes rarely become negative. Surface sensible heat fluxes during $\mathrm{CAO}$ events are on average more than twice as large as the winter median; taking into account the distribution of surface sensible heat fluxes, the difference between winter season and CAO events is even larger, as the distribution of the winter season surface sensible heat fluxes is skewed toward low values (Fig. 5g). Median surface sensible heat fluxes during $\mathrm{CAO}$ events over the rooting region are around $250-270 \mathrm{~W} \mathrm{~m}^{-2}$, which is similar to the mean sensible heat flux just off the ice edge found by Papritz and Spengler (2017) in their "Svalbard" region. As pointed out by Renfrew and Moore (1999) and Papritz et al. (2015), the cold temperatures during CAO conditions essentially provide an upper limit for latent heat fluxes during $\mathrm{CAO}$ conditions, explaining the moderate increase in latent heat fluxes during CAO events, compared to the sensible heat fluxes, and the relatively large overlap between the distribution during the winter season and CAO events (Fig. 5h).

The distribution of the wind speed at $800 \mathrm{hPa}$ during CAO events is rather similar to the winter season distribution, although over the Labrador Sea the relative frequency of occurrence for stronger wind speeds is higher during the winter season, likely due to extratropical cyclones entering the Labrador Sea from the south (Fig. 5i). This finding is in contrast to Kolstad (2017), who found an increase in wind speed during CAO conditions in the North Atlantic subpolar seas. However, in his study variables are area-averaged over the respective ocean basins and he points out that the enhanced wind speeds during $\mathrm{CAO}$ conditions in these regions are attributable to interactions with local orography (e.g., the Greenland tip jet for the Labrador Sea and Irminger Sea region; cf. Moore and Renfrew 2005), and thus the enhanced wind speeds during CAOs in Kolstad (2017) are primarily related to mesoscale features associated with the CAOs, rather than an enhanced translation velocity of the $\mathrm{CAO}$ air mass itself.

\section{b. An illustrative cold-air outbreak event}

To gain some familiarity with our collection of CAO events and PMCs, we briefly describe the evolution of a CAO event over the Fram Strait region during which multiple mesoscale cyclones developed.

The onset of the event is associated with a large-scale cold upper-level trough over the rooting region and two small synoptic-scale cyclones, one just off the Norwegian coast and the other over the Barents Sea. Together they maintain a weak northerly flow over the Fram Strait and the Greenland Sea region, quasi-parallel to the coast of Greenland during the onset of the CAO event (Fig. 6a). Initially, the CAO depth is at or below $200 \mathrm{hPa}$ nearly everywhere, except just off the ice edge over Fram Strait and the Barents Sea, with relative high values of CAO-index ${ }_{800}$ only over the rooting region. At this stage strong surface sensible and latent heat fluxes $\left(>200 \mathrm{~W} \mathrm{~m}^{-2}\right)$ are confined to regions north of and along the western coast of Svalbard (not shown).

Two days later, at the midpoint of the CAO event, the cyclone next to the Norwegian coast has dissipated, and the mean low-level flow conditions over the Greenland, northern Norwegian, and Barents Seas are dominated by a weak synoptic-scale cyclone centered over Franz Josef Land, and are encompassed by the CAO air mass. The maritime region south and southeast of the rooting area (Fram Strait) is characterized by a CAO depth $>400 \mathrm{hPa}$. During the first half of the CAO event several mesoscale cyclones developed in proximity to the CAO air mass (their tracks are shown in Figs. 6c, 6d, and 6f). The downstream progression of the CAO air mass results in significant surface turbulent heat and moisture exchange over the Greenland, northern Norwegian, and Barents Seas (Fig. 6d), and in addition the strong wind speeds and temperature anomalies associated with the PMCs locally enhance the surface fluxes. In fact, the surface latent heat fluxes associated with the PMCs are comparable to values along the ice edge.

Toward the end of the CAO event, the CAO air mass has progressed farther southward and thus the deepest CAO depths are found farther downstream, with larger values $(>500 \mathrm{hPa})$ extending all the way to the Norwegian coast and into the Barents Sea (Fig. 6e). In conjunction with this CAO development the region of high surface sensible and latent heat fluxes extends to the Norwegian coast (not shown). Notice the marked zone of confluence at the southwestern boundary of the CAO air mass, where warmer air associated with the southerly flow over Iceland impinges on the CAO air mass, resulting in a distinct boundary between the two air mass and thus a strong gradient in the CAO depth (and surface fluxes; not shown).

Altogether, this case illustrates the utility of our identification of CAO events based on a rooting region and deviations from the climatological mean, as well as the behavior of the two $\mathrm{CAO}$ metrics during a CAO event. The CAO depth increases during the evolution of the air mass with its peak location propagating downstream as the air mass matures (i.e., it evolves with the CAO air mass). In contrast, the CAO index is more spatially fixed with peak values confined to higher SSTs closer to the sea ice. Figure $6 \mathrm{~b}$ shows a satellite image representative of the midpoint of the CAO event. In it, the mesoscale cyclonic cloud signatures are easily identifiable and correspond to the PMCs automatically detected in the lowlevel vorticity field (Fig. 6f), illustrating the ability of ERA5 
(a)

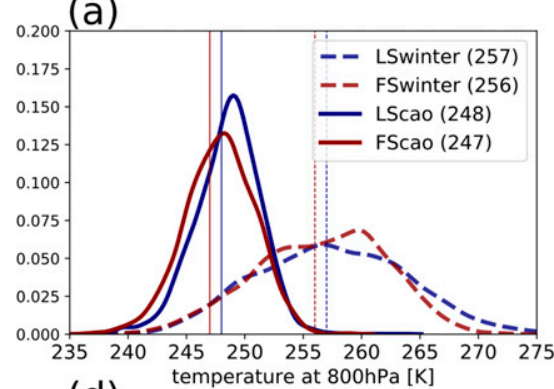

(b)

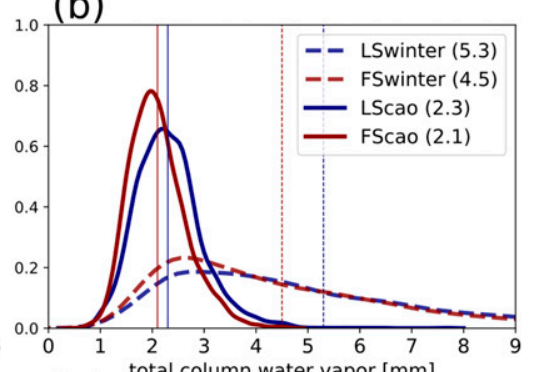

(c)

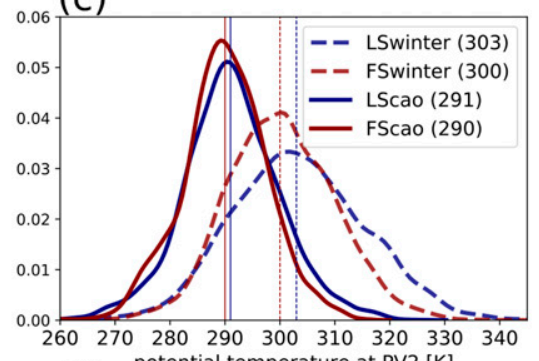

(f)

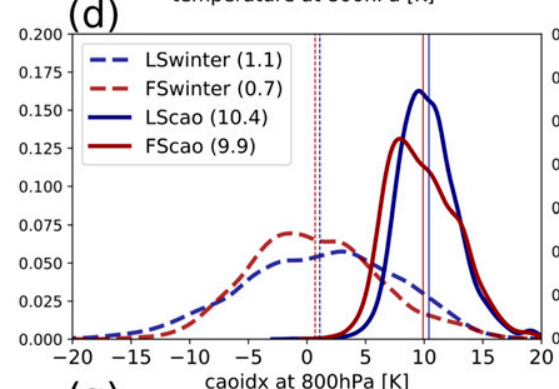

(e)
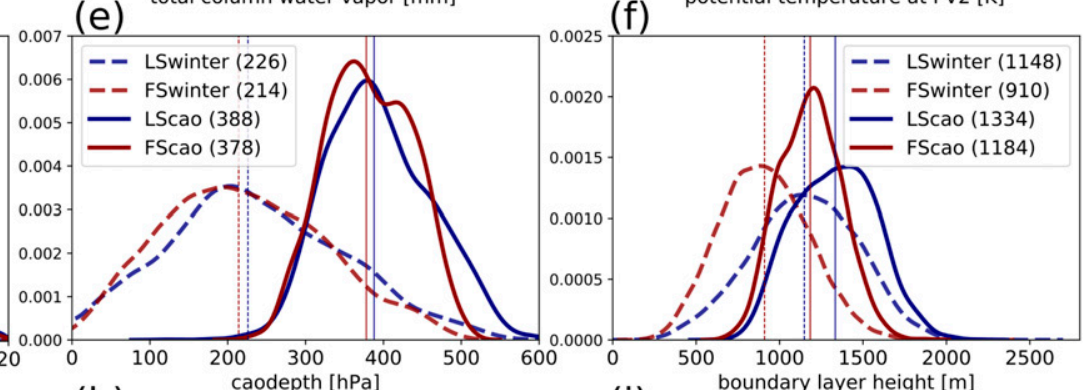
(i)
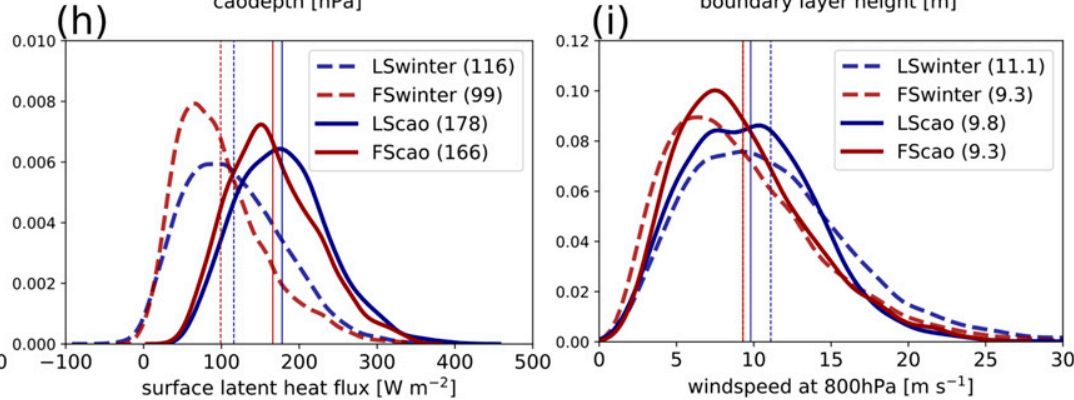

FIG. 5. Characteristics of CAO rooting regions over the Labrador Sea (LS; blue) and the Fram Strait (FS; red) during the winter season (November-March 2002-18); for locations see Fig. 1b. Values are area averaged over a radius of $100 \mathrm{~km}$; shown are kernel density estimates for each variable (as labeled) during the winter season (dashed lines) and during CAO events (solid lines). Median values for the respective distributions are marked with thin lines and noted in parentheses in the legend.

and the PMC-tracking scheme to resolve and track such mesoscale cyclone development.

\section{c. Temporal evolution of cold-air outbreak events}

We now examine the temporal evolution of CAO events for both rooting regions by using composites of our collection of CAO events. For simplicity we consider only three phases: the onset and decay are defined as the times when the CAO-in$\operatorname{dex}_{800}$ in the rooting region crosses the threshold value, and the midpoint is halfway through the event. Recall that the mean duration of our CAO events is about 3-4 days, but the range of durations is from 1 to 18 days. Note that prior to an event onset weaker CAO conditions can occur; furthermore, the intensity of the $\mathrm{CAO}$-index 800 over the rooting region usually waxes and wanes during $\mathrm{CAO}$ events (not shown). Keeping in mind these limitations, the composites provide some insights in the atmospheric configuration and temporal evolution of CAO events.

The composite of CAO events over the Labrador Sea is characterized by a synoptic-scale cyclone positioned between Iceland and southeast Greenland, so the accompanying lowlevel flow pattern is parallel to the Labrador Sea basin
(Fig. 7a). The onset of CAO events is accompanied by a cold upper-level trough (Fig. 7b), centered just north of the rooting region, and thus the flow direction at $500 \mathrm{hPa}$ is nearly perpendicular to the low-level wind direction over the rooting region. The off-ice flow of cold continental air over the Labrador Sea results in strong surface heat fluxes, which intensify and extend farther eastward as the CAO matures (Figs. 7b,d,f). The downstream development of the CAO air mass seems to be dominated by the circulation of the synoptic low and, after passing the southern tip of Greenland, it is deflected into the Irminger Sea; meanwhile the upper-level trough extends in the direction of the low-level CAO air mass as the CAO matures. Thus, in addition to effectively extracting heat from the ocean in the Labrador Sea, these events are also associated with enhanced surface heat fluxes over the Irminger Sea. This extension of CAO air masses originating in the Labrador Sea into the Irminger Sea region was previously noted by Moore and Renfrew (2005), Sproson et al. (2008), Kolstad et al. (2009), and Våge et al. (2009). The deflection of the cold air mass by Greenland results in enhanced wind speeds along the tip of Greenland, features 
(a)

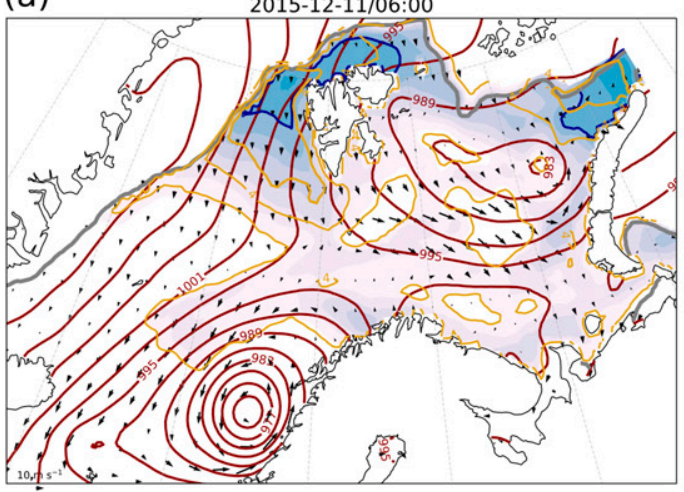

(c)
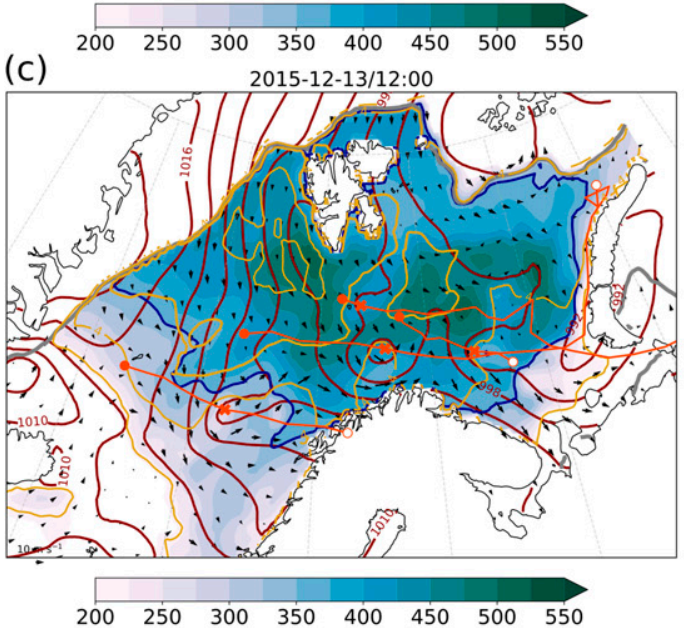

(e)

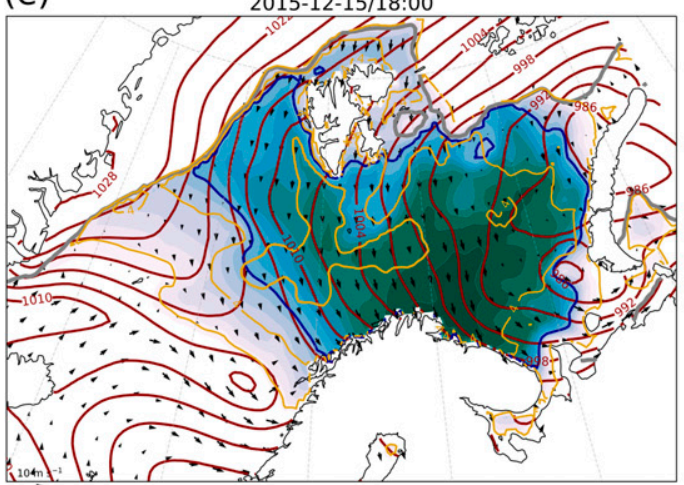

$\begin{array}{llllllll}200 & 250 & 300 & 350 & 400 & 450 & 500 & 550\end{array}$ (b)

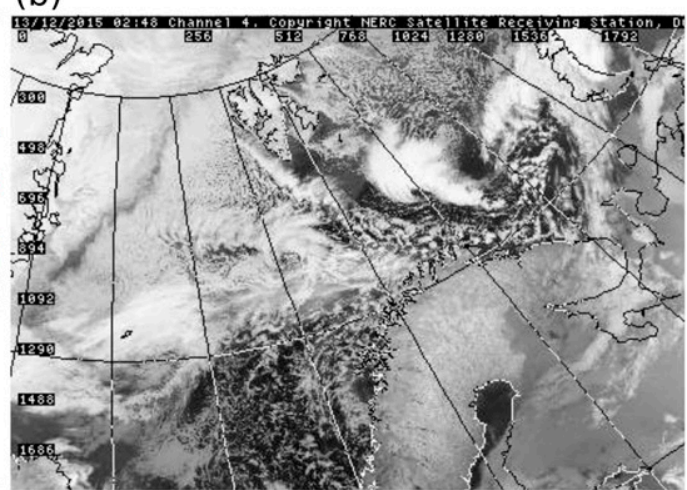

(d)

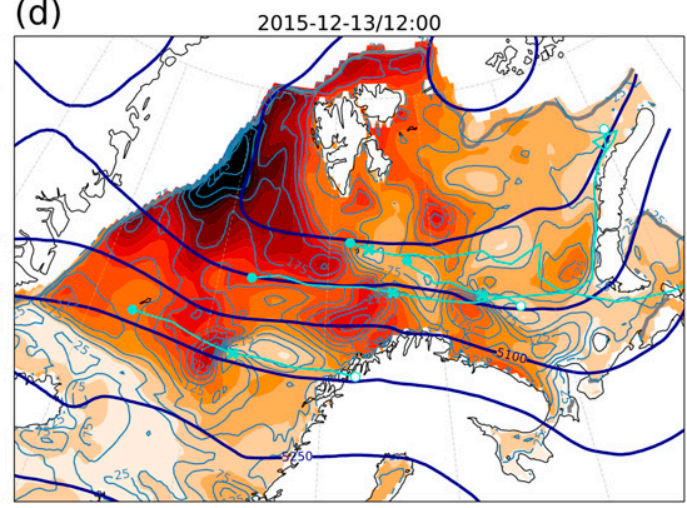

(f)

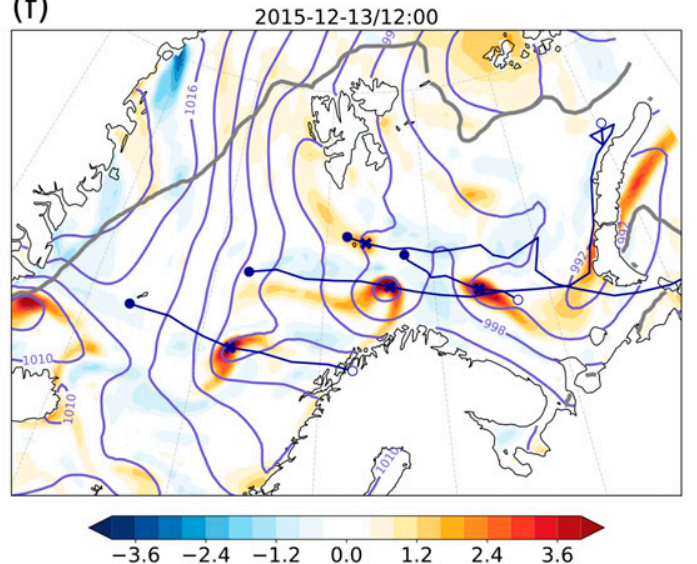

FIG. 6. Temporal evolution of an exemplar CAO case. (left) CAO depth (shading; units: hPa), mean sea level pressure (red lines; units: $\mathrm{hPa}$ ), $\mathrm{CAO}$-index ${ }_{800}$ (contour interval: $2 \mathrm{~K}$; yellow lines), $\mathrm{CAO}$ depth $=350 \mathrm{hPa}$ (blue line), and velocity vectors at $800 \mathrm{hPa}$ during the (a) onset, (c) midpoint, and (e) decay of the CAO event. (right) Shown at the midpoint of the CAO event are (b) an AVHRR satellite image at 0429 UTC 13 Dec 2015; (d) surface sensible heat flux (shading; units: $\mathrm{W} \mathrm{m}^{-2}$ ), surface latent heat flux (blue lines; units: $\mathrm{W} \mathrm{m}^{-2}$ ), and geopotential height at $500 \mathrm{hPa}$ (blue lines; units: $\mathrm{m}$ ); and (f) relative vorticity at $900 \mathrm{hPa}$ (shading; units: $\times 10^{-4} \mathrm{~s}^{-1}$ ) and mean sea level pressure (blue lines; units: hPa). Gray lines indicate the sea ice edge and the tracks of detected PMCs are indicated with thick lines (orange/cyan/blue), filled circles represent the genesis location, open circles the lysis location, with $\times$ indicating the PMCs' location at the respective time stamp. 
(a) composite of CAO events $(n=93)$, phase: onset

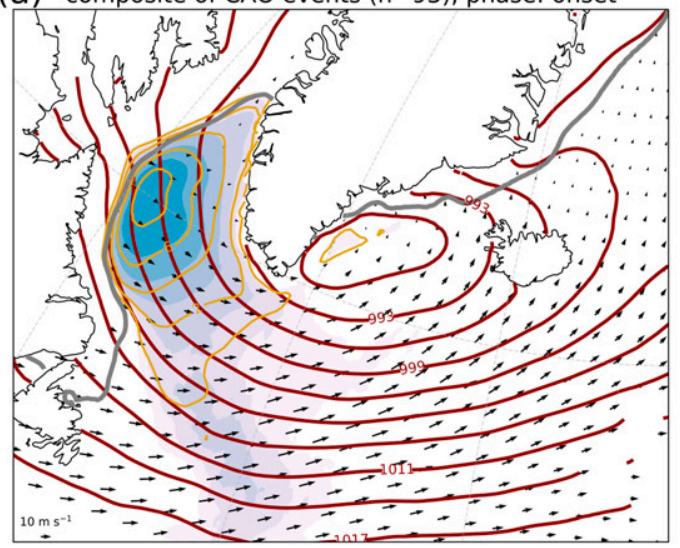

(C) composite of CAO events $(n=93)$, phase: mid-point

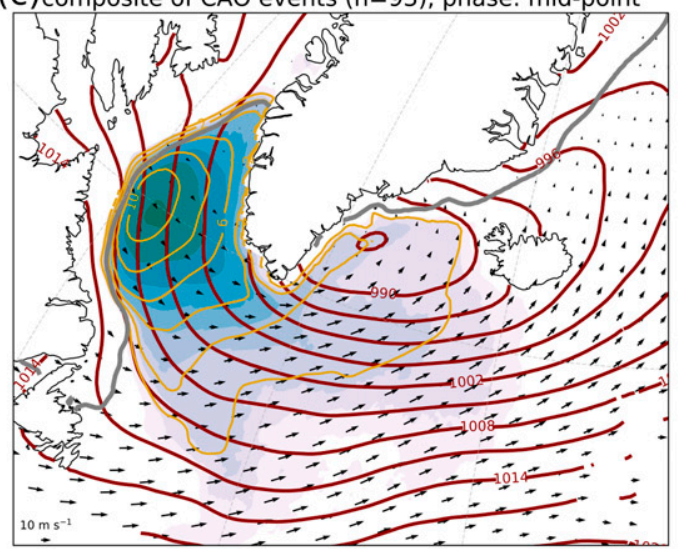

(e) composite of CAO events ( $n=93)$, phase: decay

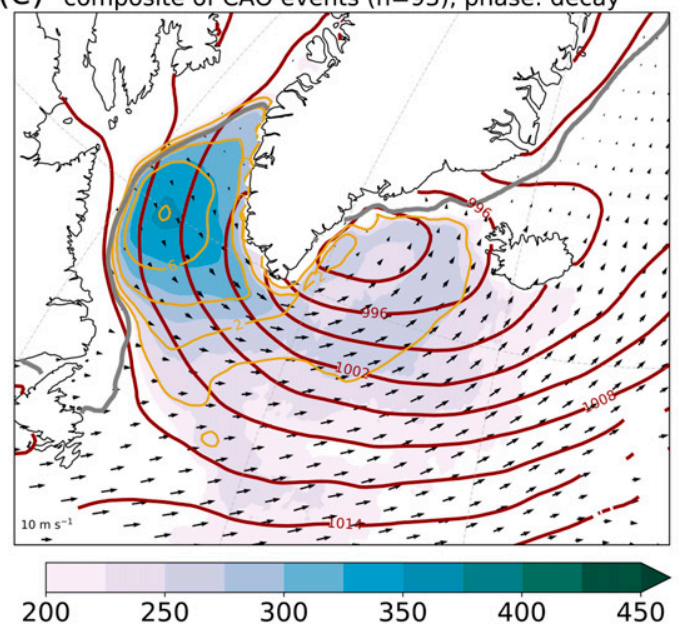

(b) composite of CAO events ( $n=93$ ), phase: onset

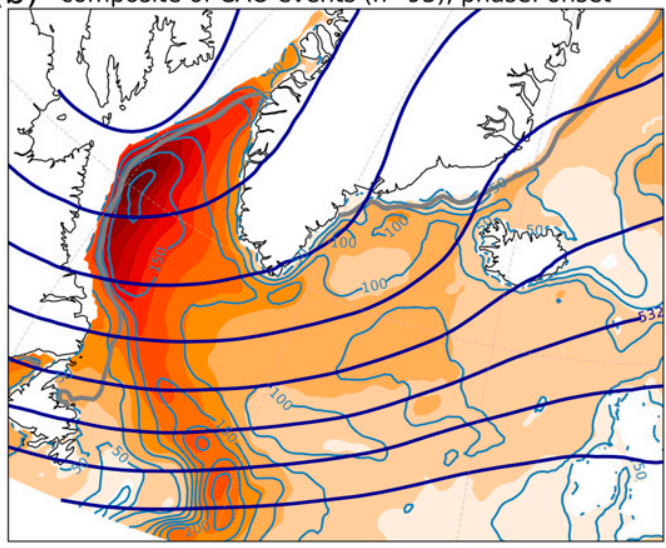

(d) composite of CAO events ( $n=93$ ), phase: mid-point

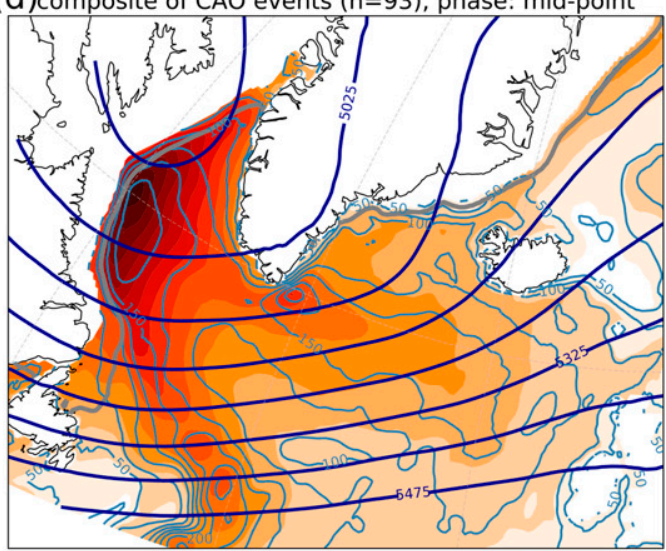

(f) composite of CAO events $(n=93)$, phase: decay

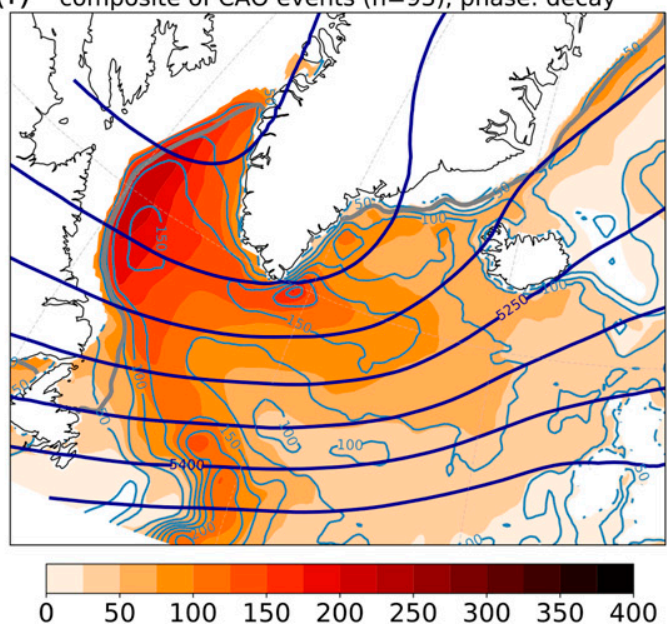

FIG. 7. Composites for CAO events rooting over the Labrador Sea (November-March 2002-18) for the (a),(b) onset, (c),(d) midpoint, and (e),(f) decay phase of the CAO events. (left) CAO depth (shading; units: hPa), mean sea level pressure (red lines; units: $\mathrm{hPa}$ ), wind at $800 \mathrm{hPa}$ (arrows; see reference vector), and CAO-index 800 (yellow lines; units: K). (right) Surface sensible heat fluxes (shading; units: $\mathrm{W} \mathrm{m}^{-2}$ ), surface latent heat fluxes (thin blue lines; units: $\mathrm{W} \mathrm{m}^{-2}$ ), and geopotential height at $500 \mathrm{hPa}$ (blue lines; units: $\mathrm{m}$ ). Thick gray lines indicate the sea ice edge ( sea ice $=0.2)$. 
known as westerly tip jets, with enhanced oceanic heat extraction along the tip jet region (Doyle and Shapiro 1999; Moore and Renfrew 2005). The composites for intense CAO events over the Labrador Sea strongly resemble the composites from Våge et al. (2009) of westerly Greenland tip jet events. Hence, not only are these tip jets preceded by CAO events, but $\mathrm{CAO}$ events are also associated with the presence of westerly tip jets.

Papritz (2017) considered CAO events over the Irminger Sea. He imposed a threshold on the CAO index $>4 \mathrm{~K}$, whereafter CAO events are defined by the 95th percentile. His composite of westerly events is rather different than composites for our CAO events originating over the Labrador Sea. According to his study, the strongest local anomalous airsea temperature differences are associated with flow off Greenland's ice sheet (i.e., katabatic flows). CAO air masses originating over the Labrador Sea and subsequently progressing into the Irminger Sea experience a significantly longer fetch over the open ocean compared to local katabatic flow reaching the Irminger Sea. Thus, these maritime CAO air masses do not exhibit the largest air-sea temperature differences over the Irminger Sea. Yet their heat extraction from the ocean occurs for a much longer duration and covers a larger spatial extent than katabatic flows (Oltmanns et al. 2014); furthermore, their higher temperatures increase the potential for stronger surface latent heat fluxes.

The composite evolution of CAO events originating over the Fram Strait region also features a synoptic-scale low to the east of the CAO rooting region and an upper-level trough toward the north (Figs. 8a,b). Similar to the Labrador Sea composite the circulation associated with this low pressure system deflects the downstream evolution of the CAO air mass southward and eastward, in this case into the Barents Sea. The synoptic-scale low is located such that the southerly component of the low extends into the Iceland Sea, resulting in the CAO air mass extending well into the Greenland and Norwegian Seas. High surface heat fluxes are initially confined to the Greenland Sea, but extend all the way to the Norwegian coast as the CAO progresses, with a clear imprint of the underlying sea surface temperatures (e.g., evident in the banded structure of strong surface fluxes over the Greenland Sea). Peak surface fluxes are found over the rooting region, whereas farther downstream a large area experiences moderate sensible heat fluxes, accompanied by comparable surface latent heat fluxes. Notice the development of a cyclone over Iceland, supplying warm, moist air from the south and resulting in a distinct boundary of the CAO air mass over the Iceland and Norwegian Seas.

\section{Polar mesoscale cyclogenesis during cold-air outbreak events}

\section{a. Collocation of PMCs and CAO events}

We now examine the collocation of CAO events and PMCs. Note that our collection of CAO events is based on the two specified rooting regions, so it does not include CAO events that may be significant in the respective ocean basins if they do not impact the rooting regions. For the Labrador Sea and Fram Strait regions the spatial extents of the composite CAO air masses are used as a guide to define larger regions of interest (see boxes in Fig. 9). For consistency we will refer to these domains by their respective rooting regions. PMCs are attributed to $\mathrm{CAO}$ events if their genesis is located within these respective regions during a $\mathrm{CAO}$ event and in the proximity of a cold air mass. The proximity condition is satisfied if the PMC is within $150 \mathrm{~km}$ of a CAO (defined as where the CAO height $<800 \mathrm{hPa}$ ). This condition was chosen after inspection of several case studies.

In total we detect 1654 (1240) PMCs during the 16 winter seasons (2002-18) over the Labrador Sea (Fram Strait) region, of which 235 (167) are linked to our collection of CAO events. The area of the ice-free maritime region in the Labrador Sea is about twice the size of the Fram Strait region; hence, despite lower absolute values, the PMC genesis density is larger in the Fram Strait region. Figure 9 displays the PMC tracks that are associated with our collection of CAO events. They do not tend to cluster, but rather cover the entire region encompassed by the CAO air masses as identified by the composite analysis (see Figs. 7 and 8). Noteworthy is the relatively low number of PMCs over the Greenland Sea (i.e., over the cold waters next to the sea ice east of Greenland) and a higher number of PMCs over the adjacent Norwegian Sea, hinting at the role of SSTs for PMC initiation during CAO events.

Recall that during the winter season CAO events based on sustained CAO conditions over the rooting regions occur $15 \%$ $\pm 9 \%$ and $13 \% \pm 7 \%$ of the time, for the Labrador Sea and the Fram Strait region, respectively. The PMC genesis associated with these CAO events is only $14 \% \pm 10 \%$ for both regions. Thus, the fraction of winter season PMCs that develop during these CAO events is similar to the CAO event frequency. The average PMC genesis per day during the winter season is 0.68 $\pm 0.16(0.51 \pm 0.08)$ for the Labrador Sea (Fram Strait) region, and associated with the identified CAO events is $0.58 \pm 0.27$ $(0.46 \pm 0.23)$, respectively. Hence, the mean PMC genesis during these $\mathrm{CAO}$ events is slightly reduced for both regions compared to the winter season, likely due to the restricting requirement of the proximity of a CAO.

We have also examined the numbers of PMCs per CAO event and these are rather similar for the two regions (Fig. 10a). Both regions have a peak of zero PMCs $(30 \%$ and $37 \%$ of CAO events for the Labrador Sea and the Fram Strait regions), with 1 or 2 PMCs per CAO event more common than higher numbers of PMCs. The median and lower and upper quartiles of PMCs per CAO event are 1, 0, and 3 over the Labrador Sea and 1, 0, and 2.5 over the Fram Strait region (Table 1). We also considered the rate of PMC genesis $\left(\right.$ day $\left.^{-1}\right)$ as this controls for the different durations of $\mathrm{CAO}$ events. When we ignore CAO events without PMCs, the rate of PMC genesis during CAO events is approximately normal (Fig. 10b). The median and lower and upper quartiles are $0.63,0.42$, and 0.98 day $^{-1}$ for the Labrador Sea and $0.66,0.51$, and $0.93 \mathrm{day}^{-1}$ for the Fram Strait region, thus remarkably similar for the two regions. Longer $\mathrm{CAO}$ events have more PMCs, but this is due to their duration; the cyclogenesis rate is comparable to shorter CAO events. 
(a) composite of CAO events ( $n=95)$, phase: onset

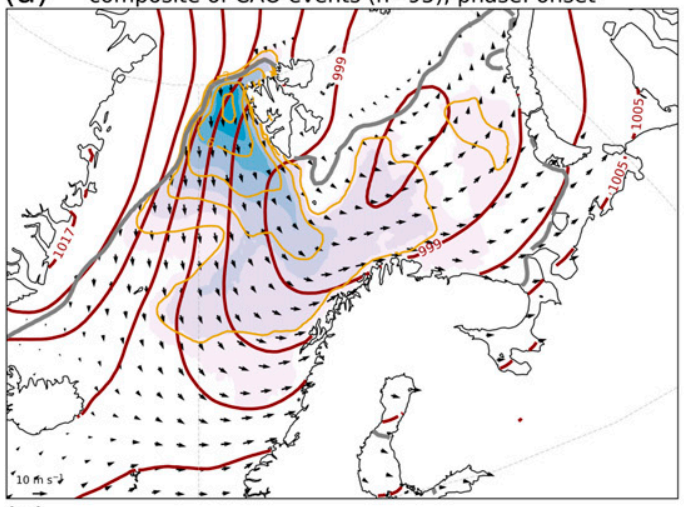

(C) composite of CAO events ( $n=95)$, phase: mid-point

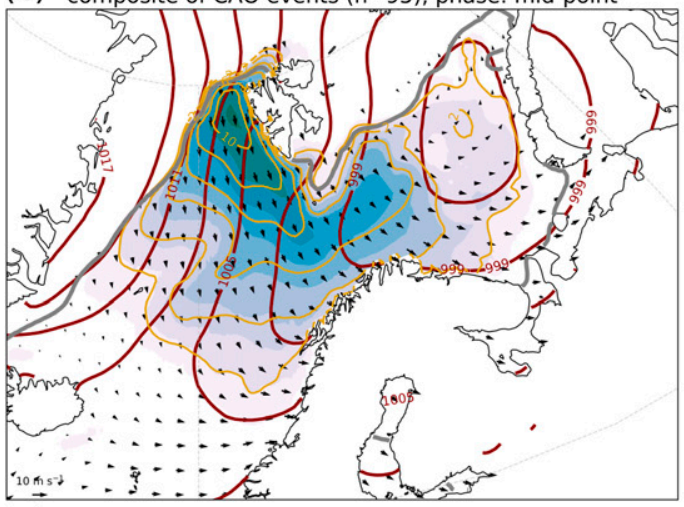

(e) composite of CAO events ( $n=95)$, phase: decay

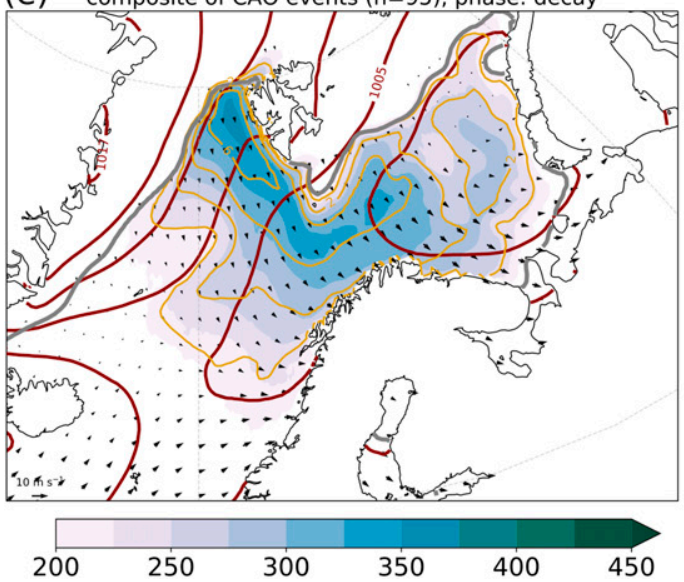

(b) composite of CAO events ( $n=95)$, phase: onset

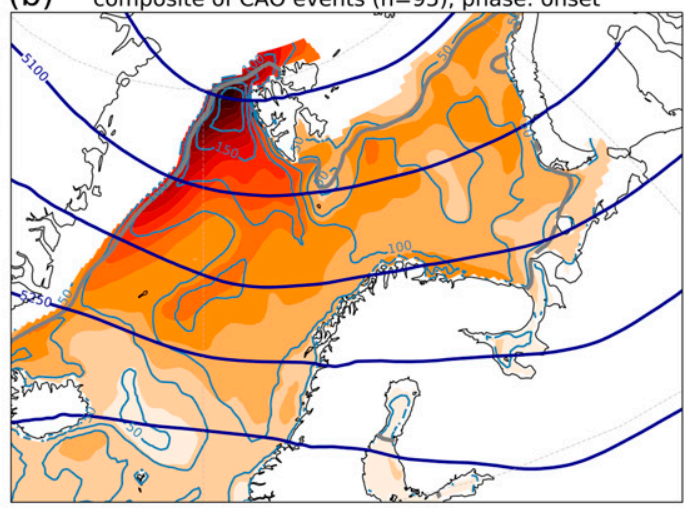

(d) composite of CAO events ( $n=95$ ), phase: mid-point

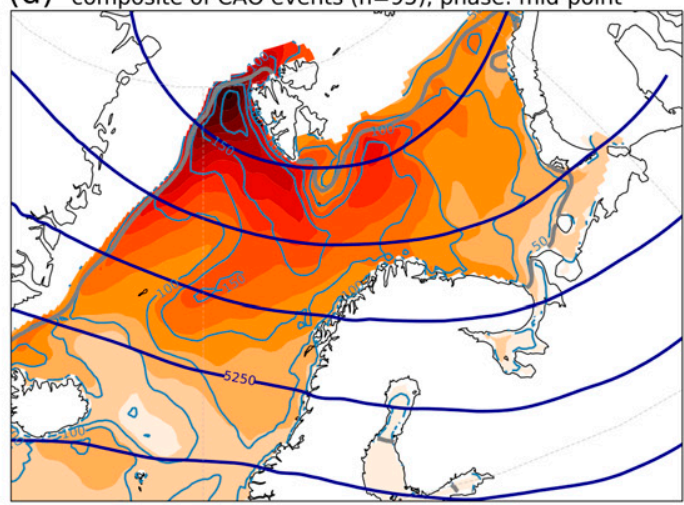

(f) composite of CAO events ( $n=95)$, phase: decay

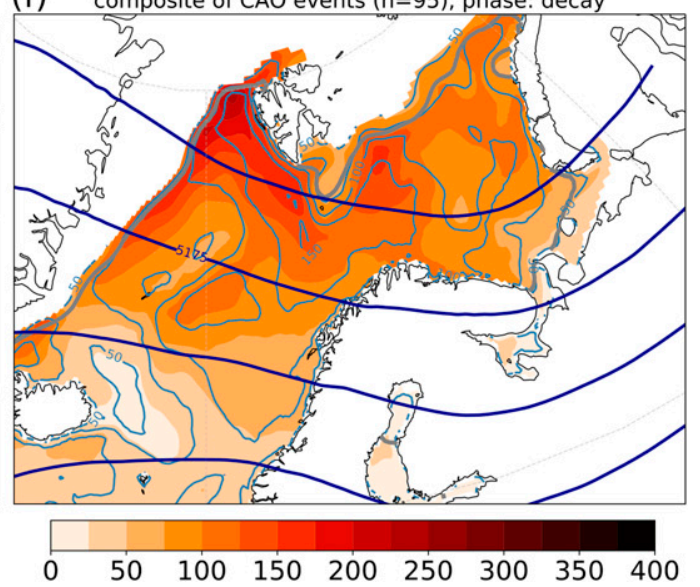

FIG. 8. Composites for CAO events rooting over the Fram Strait (November-March 2002-18) for the (a),(b) onset, (c),(d) midpoint, and (e),(f) decay phase of the CAO events. (left) CAO depth (shading; unit: hPa), mean sea level pressure (red lines, units: hPa), wind at $800 \mathrm{hPa}$ (arrows, see reference vector), and CAO-index $\mathrm{x}_{800}$ (yellow lines; unit: K). (right) Surface sensible heat fluxes (shading; unit: $\mathrm{W} \mathrm{m}^{-2}$ ), surface latent heat fluxes (thin blue lines; unit: $\mathrm{W} \mathrm{m}^{-2}$ ), and geopotential height at $500 \mathrm{hPa}$ (thin blue lines; unit: $\mathrm{m}$ ). Thick gray lines indicate the sea ice edge $($ sea ice $=0.2)$.

Thus, the longevity of a CAO event is not related the rate of PMC genesis.

PMCs develop throughout $\mathrm{CAO}$ events, with a marginal preference for more PMCs during the first half of $\mathrm{CAO}$ events over the Fram Strait region and during the second half of $\mathrm{CAO}$ events over the Labrador Sea region (Fig. 11). The first occurrence of a PMC during a CAO event is predominantly in the first third of the CAO event in both regions.

Our collection of PMCs, based on the selection criteria described in section 2, includes only PMC genesis over the icefree ocean. However, previous studies have shown that both sea ice and orography can play a role in polar low genesis (e.g., 

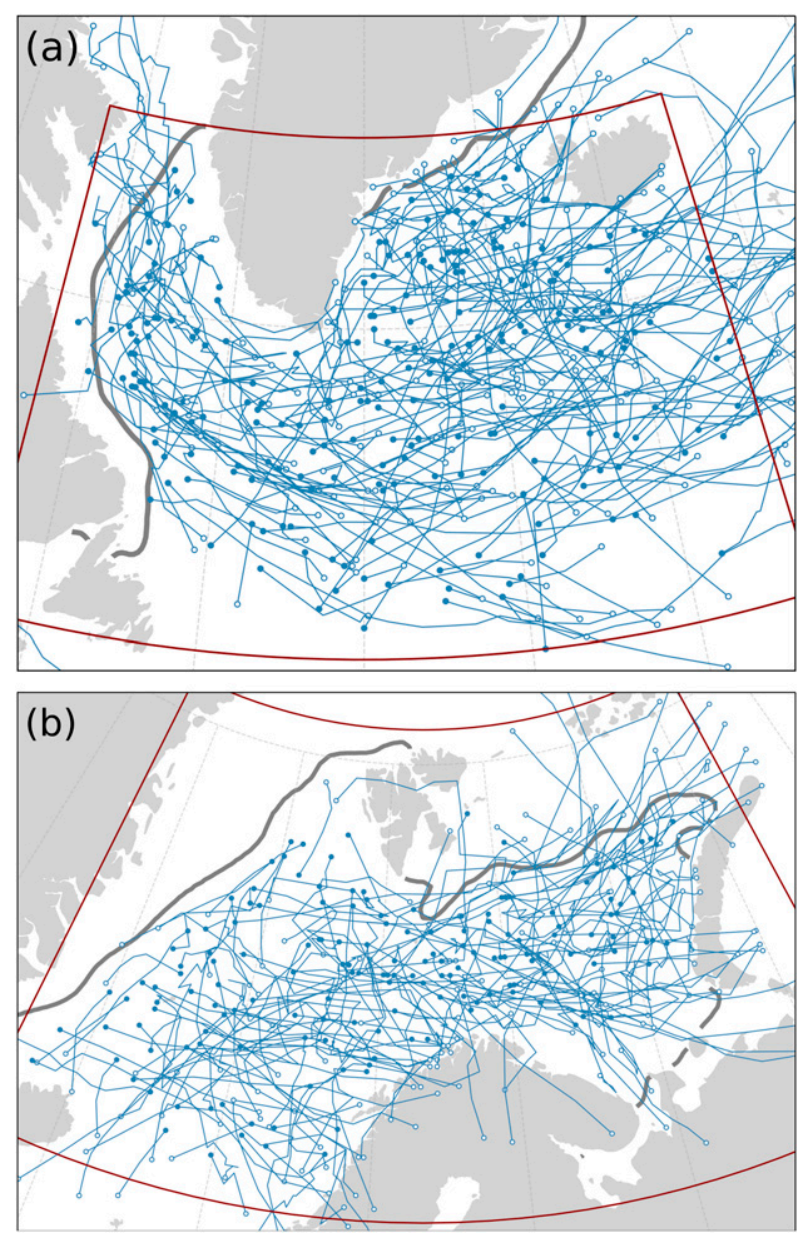

FIG. 9. Tracks of polar mesoscale cyclones developing during CAO events in (a) the Labrador Sea and (b) the Fram Strait region. Individual tracks are shown by lines, filled circles indicate the genesis, and open circles the lysis location. Red lines indicate the boundaries of the respective regions. The thick solid line corresponds to the winter-mean sea ice edge (

Pagowski and Moore 2001; Sergeev et al. 2018). Including nonmaritime PMC genesis increases the number of PMCs per CAO events by about $40 \%$ (Table 1 ). However, even with the inclusion of these additional PMCs, the number of CAO events without PMCs remains significant, namely 24\% (27\%) for the Labrador Sea (Fram Strait) region.

We have also tested the effect of restricting our PMCs to be proximal to $\mathrm{CAO}$ conditions. Using the criterion of being proximal (i.e., the distance to a CAO depth of $800 \mathrm{hPa}<$ $150 \mathrm{~km}$ ) includes $85 \%(78 \%)$ of PMCs in the Labrador Sea (Fram Strait) basin, so most PMCs develop inside or in close proximity of the CAO air mass. Here we ease this restriction by including any PMCs in the region during CAO events. This slightly enhances the total number of detected PMCs during a CAO event, over both locations, although roughly a third of the CAO events (29\%) remain without PMCs (Table 1).

Overall our results indicate that $\mathrm{CAO}$ events are a rather poor predictor of PMC genesis. In roughly a third of all
CAO events no PMC development occurred. The lack of PMC genesis during these events potentially contributes to a relatively large interseasonal variation in CAO-related cyclogenesis. These findings also explain why Michel et al. (2018) did not find a good match between PMC genesis and several CAO metrics. In short, PMC genesis rates during CAO are comparable to those during the winter season generally. Note that these findings are similar for both regions independently, and also for other regions we have examined.

\section{b. Characteristics of polar mesoscale cyclone genesis}

We now consider the genesis conditions of PMCs that develop during $\mathrm{CAO}$ events and during the entire winter season; here we use PMCs as defined in section 2, where their genesis is over the ice-free ocean. Note that PMCs during CAO events are a subset of PMCs during the winter season.

In line with the developing cold air mass, PMC genesis conditions during CAO events are generally 4-5 K colder and significantly dryer than during the winter season (Figs. 12a,b). Labrador Sea PMC genesis takes place in a warmer and moister environment than Fram Strait PMC genesis, both during the winter season and during CAO conditions. Climatologically the height of the tropopause decreases with latitude, and this is reflected in the distribution of potential temperature at the dynamical tropopause during winter season PMC genesis, as the more southerly region (the Labrador Sea) exhibits a wider distribution including higher potential temperatures at the dynamical tropopause (Fig. 12c). During CAO events these distributions become more similar, with both showing low potential temperatures at the dynamical tropopause (i.e., low tropopause heights) during PMC genesis. Note that we used a value of 2 PVU at $315 \mathrm{~K}$ (see section 2) to exclude mesoscale cyclones associated with the main baroclinic jet, hence the lack of PMC genesis with higher potential temperatures at the dynamical tropopause.

The median CAO index during PMC genesis is 1.8 (2.7) $\mathrm{K}$ for the two regions, but note that a significant fraction of PMCs occur during a negative CAO index, together with a rather large overlap between winter season and CAO-related PMC genesis conditions (Fig. 12d). This demonstrates one limitation of using the $\mathrm{CAO}$ index metric for associating $\mathrm{CAO}$ events and PMCs. With increasing fetch over the open ocean, a $\mathrm{CAO}$ air mass is modified by surface energy exchange; typically the air mass warms and moisture content increases, resulting in a destabilization and deepening of the atmospheric boundary layer (e.g., Brümmer 1997). In agreement with this scenario, PMC genesis associated with CAO events has a reduced low-level static stability, calculated as the vertical gradient of potential temperature between 950 and $700 \mathrm{hPa}$, compared to winter mean PMC genesis (Fig. 12i). Reduced static stability is also reflected by a greater CAO depth, with the median shifted more than $120 \mathrm{hPa}$, for PMC genesis during CAO conditions (Fig. 12e), as well as in increased boundary layer heights (Fig. 12f). The greater CAO depths also imply that PMC genesis predominantly takes place inside the air mass during CAO events, as opposed to at the periphery. Notice that the shapes of the histograms for the CAO depth 

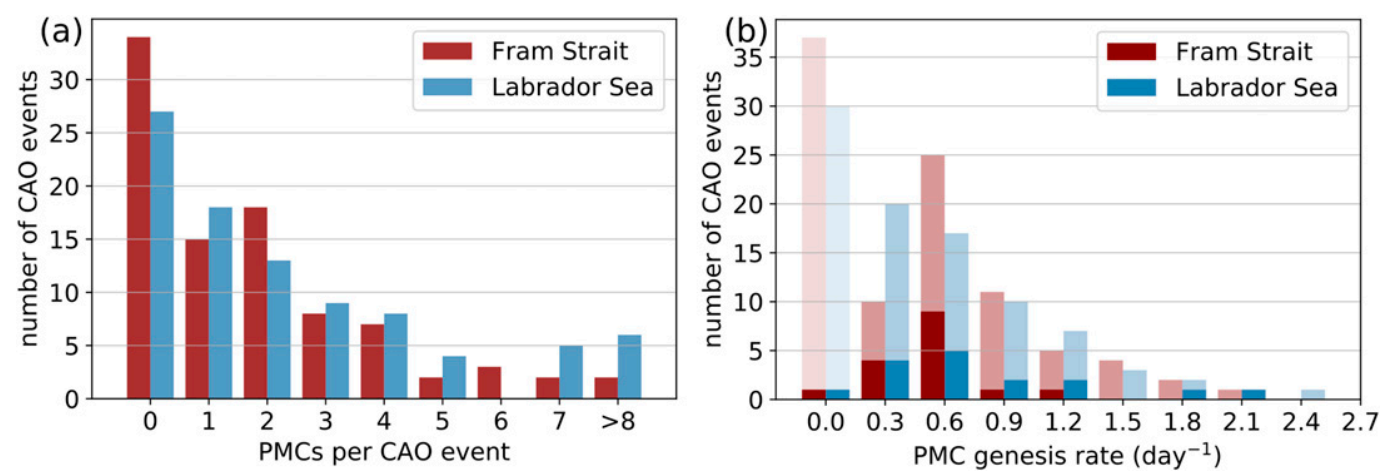

FIG. 10. (a) Number of polar mesoscale cyclones per CAO event for the Labrador Sea (blue) and the Fram Strait region (red) during the winter season and (b) PMC genesis rates (units: day ${ }^{-1}$ ) during all CAO events (light), during CAO events with PMCs (medium), and during long-lasting CAO events (dark). A long-lasting CAO event has a duration $>85$ th percentile of all CAO events, which is 6.9 (5.5) days for the Labrador Sea (Fram Strait) region.

and static stability are similar in both regions, both for PMC genesis during CAO events or during the winter season.

CAO events are often associated with anomalous surface heat and moisture exchange due to the large air-sea temperature differences, and this is reflected in the surface energy exchange for PMC genesis during CAO events (Figs. 12g,h). The distribution of the surface heat flux is shifted toward higher values, with median surface sensible heat fluxes around $80-90 \mathrm{~W} \mathrm{~m}^{-2}$ during PMC genesis. The distributions for surface sensible heat fluxes and CAO index are rather similar for both regions, reflecting that the air-sea temperature differences are similar during PMC genesis for both regions. However, the atmosphere is warmer over the Labrador Sea during PMC genesis, and this warmer atmosphere allows higher surface latent heat fluxes in the Labrador Sea region than in the Fram Strait region (Fig. 12h). Plausible explanations for the interbasin differences include the higher SSTs in the Labrador Sea region compared to the Fram Strait region, in particular downstream of the rooting region (see Fig. 1b), as well as the greater length and duration of fetch of the CAO air mass, and thus the total warming and moistening of the boundary layer over the Labrador Sea region.

To summarize, in general PMCs during CAO events have similar prevalence as PMCs during the winter season; however, their genesis environments exhibit distinct characteristics compared to winter season PMCs. In general there is a reduced static stability, a deeper boundary layer, and stronger surface energy exchange for PMC genesis during CAO events; furthermore, this genesis takes place in relatively dry and cold conditions. The main differences between PMC genesis conditions for the two regions are that the temperature, moisture content, and surface latent heat fluxes are higher over the Labrador Sea.

\section{Summary and conclusions}

We have examined the spatial and temporal evolution of CAO events in the Labrador Sea and Fram Strait region, demonstrated the utility of a new CAO metric, and established the characteristics of PMC genesis associated with CAO events.

Despite CAOs being primarily an atmospheric phenomena, commonly used definitions of CAO condition are based on the sea-air temperature difference, analogously to the bulk formula for sensible heat fluxes. The implication of this definition is a rather strong imprint of the spatial distribution of the sea surface temperature, with higher SSTs along the ice edge favorable for being labeled as (more intense) CAO conditions. We have compared this definition with an alternative CAO metric, the CAO depth, which is dependent on both the temperature and the static stability in the lower troposphere and so is less sensitive to a single level. The CAO depth evolves with fetch as the air mass is modified via air-sea interactions. Compared to the $\mathrm{CAO}$ index, the spatial extent of the CAO depth extends farther downstream and is less tied to the ice edge. The spatial distribution of CAO frequency more closely resembles the spatial distribution of CAO depth than that of the CAO index. The use of either CAO metric should depend on the objective of the

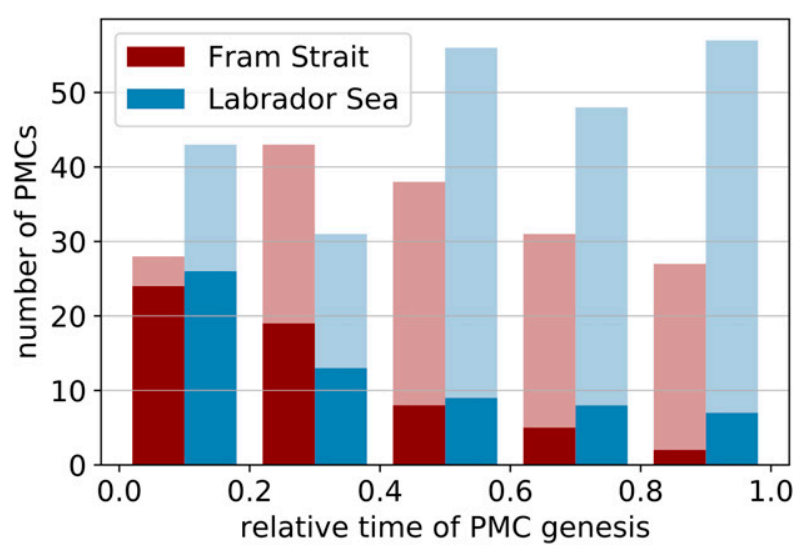

FIG. 11. The genesis time of PMCs relative to the CAO event duration for the first PMC of the CAO event (dark) and all associated PMCs (light). 
(a)

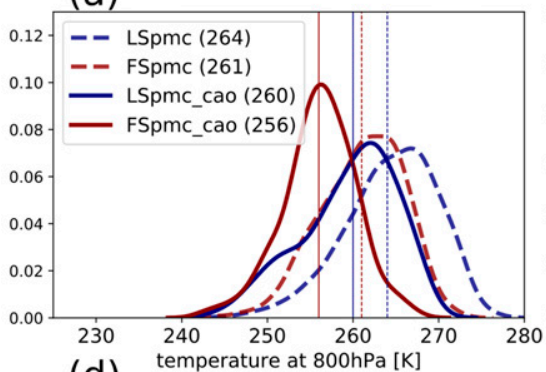

(d) (b)

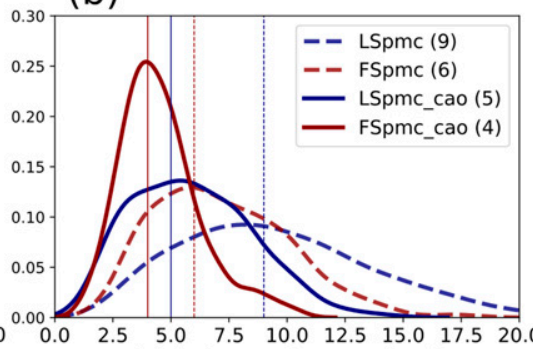

(e) (c)

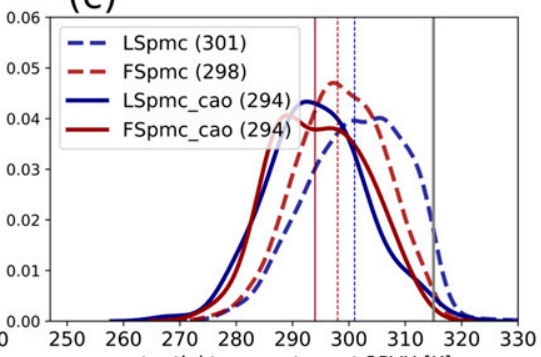

(f)
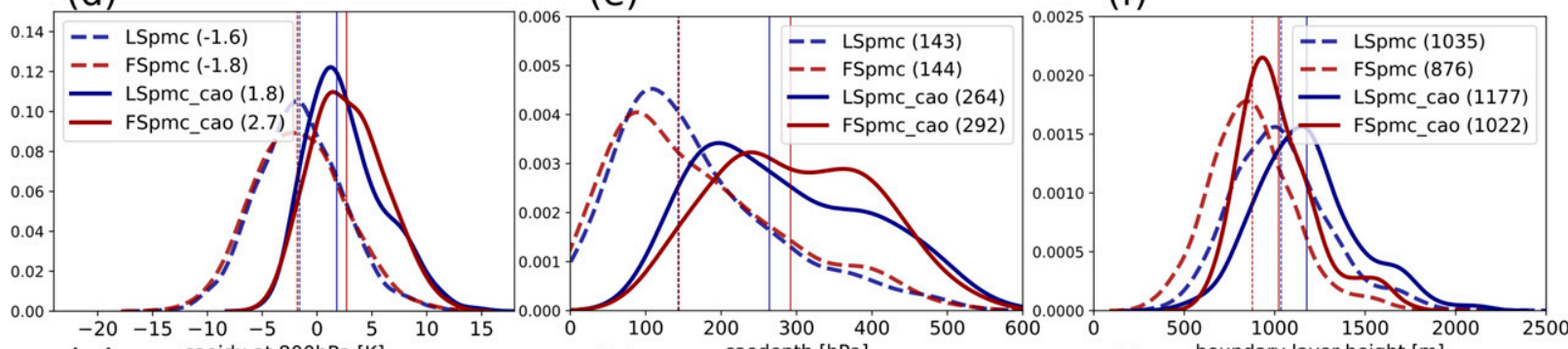

(g)
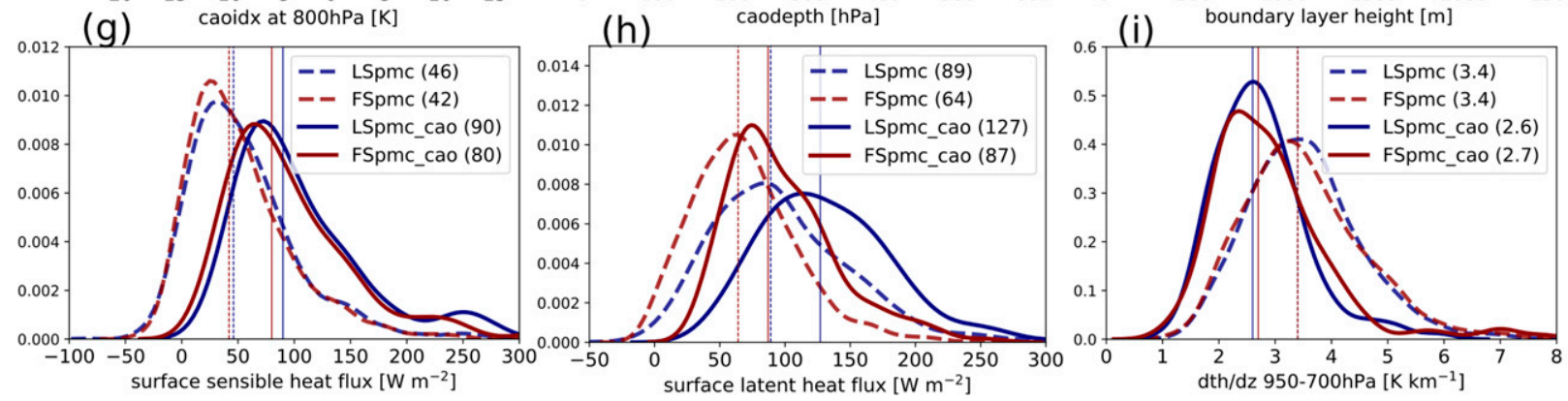

FIG. 12. Characteristics of polar mesoscale cyclone genesis over the Labrador Sea (LS; blue) and the Fram Strait (FS; red) during the winter season (November-March 2002-18) and during CAO events. Values are area-averaged over a radius of $150 \mathrm{~km}$ during genesis. Shown are kernel density estimates for each variable (as labeled) during the winter season (dashed lines) and during CAO events (solid lines). Median values for the respective distributions are marked with thin lines and noted in parentheses in the legend.

study; the CAO depth is more representative of the evolving $\mathrm{CAO}$ air mass, while the $\mathrm{CAO}$ index is more representative of the potential for surface sensible heat loss from the ocean.

One drawback of using the CAO depth is that it is computationally more expensive than the CAO index, although still cheaper than a Lagrangian approach (cf. Papritz and Spengler 2017). The CAO depth might be preferred over the CAO index in situations where the spatial extent of the CAO events matters, such as for associating CAO events with PMCs, precipitation, or the complete interaction with the underlying ocean. During the winter season in the North Atlantic region, the winter mean latent heat fluxes are larger than the sensible heat fluxes except for a narrow strip along the ice edge. Just off the ice edge the CAO air mass's low temperature, and hence low specific humidity, hinders surface latent heat fluxes, although as the CAO air mass evolves downstream the latent heat fluxes increase. Thus, a CAO definition based on the air-sea temperature differences, such as the CAO index, might not fully capture the spatial extent of the combined heat extraction from the underlying ocean.

Our collection of CAO events is based on anomalously cold events with respect to climatological conditions over the
Labrador Sea and Fram Strait. Both regions experience between 3 and $8 \mathrm{CAO}$ events per winter, with CAO events typically lasting 2-5 days and occasionally lasting longer than a week. In both regions, composite analysis shows that the off-ice lower-tropospheric flow is found at the rear of a synoptic-scale surface cyclone (i.e., the cyclone is located eastward of the $\mathrm{CAO}$ region, and is accompanied by a cold upper-level trough over the CAO region). As the CAO matures the upper-level trough and the low-level CAO air mass move eastward, with CAO events over the Labrador Sea extending into the Irminger Sea, and CAO events over the Fram Strait extending into the Barents Sea.

Despite the nearly $20^{\circ}$ difference in latitude between the Labrador Sea and Fram Strait, distributions of the temperature, surface turbulent exchange, and tropospheric structure are rather similar both during $\mathrm{CAO}$ events and the winter season. The exception is the boundary layer depth, which is greater over the Labrador Sea. The persistence of CAO conditions over the Labrador Sea is slightly higher than for the Fram Strait, both in the mean and maximum duration of CAO events. 
The results of this study indicate that most $(2 / 3)$ of CAO events are associated with PMCs, yet a significant fraction (1/3) of CAO events are not. The lack of PMC genesis during roughly a third of the $\mathrm{CAO}$ events makes them a poor proxy for PMC genesis, as over the entire winter season CAO events are not associated with enhanced PMC frequencies. PMC genesis associated with CAO events occurs over the entire life cycle of an event, and primarily within the CAO air mass. PMC genesis conditions during $\mathrm{CAO}$ events exhibit distinctly different characteristics than those of PMCs over the whole winter season. PMC genesis during CAO events takes place in a relatively cold, dry, and shallow troposphere, with enhanced surface heat exchange and a decreased static stability. In the Labrador Sea region PMC genesis conditions are often warmer and moister than the Fram Strait region, and thus accompanied by stronger latent heat fluxes and a deeper boundary layer.

Our results illustrate that CAO conditions are not sufficient for triggering PMC genesis, and thus an emerging question is the following: Why are not all CAO events associated with PMCs? With PMC genesis rates independent of the duration of $\mathrm{CAO}$ events, and PMCs occurring during all phases of $\mathrm{CAO}$ events and covering the entire CAO air mass extent, there must be some additional triggers. These would include interaction with underlying SST gradients, orographic features, the emergence of local convergence lines, or a mobile upper-level trough [see Terpstra and Watanabe (2020) for an overview of genesis triggers]. Furthermore, it is unclear if these triggers are any different during $\mathrm{CAO}$ events than during the entire winter season. The dataset provided in this study could serve as a stepping stone for further investigation of PMCs and their characteristics, both during $\mathrm{CAO}$ events and the winter season, including their interactions with the underlying ocean and their effects on the air masses that embed PMCs.

Acknowledgments. Data for this study are provided by the European Centre for Medium-Range Weather Forecasts (ECMWF) and available via the Copernicus Climate Change Service Climate Data Store (CDS). AT is supported by the Research Council of Norway as part of the project DYNAMISM (262110), and by the European Union's Seventh Framework Programme for research, technological development, and demonstration under the Marie Curie Grant Agreement 608695. IR acknowledges funding from NERC NE/N009754/1 AFIS, part of the Iceland Greenland Seas Project. DS is partly supported by a Science and Technology Facilities Council Consolidated Grant (ST/R000395/1). The code used in this study relies on the following Python libraries: Matplotlib (Hunter 2007), pandas (McKinney 2010), xarray (Hoyer and Hamman 2017), and MetPy (May et al. 2020).

\section{REFERENCES}

Brümmer, B., 1997: Boundary layer mass, water, and heat budgets in wintertime cold-air outbreaks from the Arctic sea ice. Mon. Wea. Rev., 125, 1824-1837, https://doi.org/10.1175/ 1520-0493(1997)125<1824:BLMWAH >2.0.CO;2.

—, G. Müller, and G. Noer, 2009: A polar low pair over the Norwegian Sea. Mon. Wea. Rev., 137, 2559-2575, https:// doi.org/10.1175/2009MWR2864.1.
Buckley, M. W., and J. Marshall, 2016: Observations, inferences and mechanisms of the Atlantic meridional overturning circulation: A review. Rev. Geophys., 54, 5-63, https://doi.org/ 10.1002/2015RG000493.

Chang, S. S., and R. R. Braham, 1991: Observational study of a convective internal boundary layer over Lake Michigan. J. Atmos. Sci., 48, 2265-2279, https://doi.org/10.1175/15200469(1991)048<2265:OSOACI > 2.0.CO;2.

Claud, C., G. Heinemann, E. Raustein, and L. McMurdie, 2004: Polar low le Cygne: Satellite observations and numerical simulations. Quart. J. Roy. Meteor. Soc., 130, 1075-1102, https://doi.org/10.1256/qj.03.72.

— B. Buchiron, and P. Terray, 2007: Associations between large-scale atmospheric circulation and polar low development over the North Atlantic during winter. J. Geophys. Res., 112, D12101, https://doi.org/10.1029/2006JD008251.

Condron, A., and I. Renfrew, 2013: The impact of polar mesoscale storms on northeast Atlantic Ocean circulation. Nat. Geosci., 6, 34-37, https://doi.org/10.1038/ngeo1661.

— G. R. Bigg, and I. Renfrew, 2006: Polar mesoscale cyclones in the northeast Atlantic: Comparing climatologies from ERA40 and satellite imagery. Mon. Wea. Rev., 134, 1518-1533, https://doi.org/10.1175/MWR3136.1.

Douglas, M. W., M. Shapiro, L. Fedor, and L. Saukkonen, 1995: Research aircraft observations of a polar low at the East Greenland ice edge. Mon. Wea. Rev., 123, 5-15, https://doi.org/ 10.1175/1520-0493(1995)123<0005:RAOOAP $>2.0$.CO;2.

Doyle, J. D., and M. A. Shapiro, 1999: Flow response to large-scale topography: The Greenland tip jet. Tellus, 51A, 728-748, https://doi.org/10.3402/tellusa.v51i5.14471.

Drüe, C., and G. Heinemann, 2001: Airborne investigation of Arctic boundary layer fronts over the marginal ice zone of the Davis Strait. Bound.-Layer Meteor., 101, 261-292, https:// doi.org/10.1023/A:1019223513815.

Fletcher, J. K., S. Mason, and C. Jakob, 2016a: The climatology, meteorology, and boundary layer structure of marine cold air outbreaks in both hemispheres. J. Climate, 29, 1999-2014, https://doi.org/10.1175/JCLI-D-15-0268.1.

,$- \ldots$, and $\longrightarrow, 2016 \mathrm{~b}$ : A climatology of clouds in marine cold air outbreaks in both hemispheres. J. Climate, 29, 6677-6692, https://doi.org/10.1175/JCLI-D-15-0783.1.

Harden, B., I. A. Renfrew, and G. Petersen, 2011: A climatology of wintertime barrier winds off southeast Greenland. J. Climate, 24, 4701-4717, https://doi.org/10.1175/2011JCLI4113.1.

—, , and — 2015: Meteorological buoy observations from the central Iceland Sea. J. Geophys. Res. Atmos., 120, 31993208, https://doi.org/10.1002/2014JD022584.

Harold, J. M., G. R. Bigg, and J. Turner, 1999: Mesoscale activity over the North-East Atlantic. Part I: Vortex distribution and variability. Int. J. Climatol., 19, 1187-1204, https://doi.org/10.1002/(SICI)10970088(199909)19:11<1187::AID-JOC419>3.0.CO;2-Q.

Hersbach, H., and Coauthors, 2020: The ERA5 global reanalysis. Quart. J. Roy. Meteor. Soc., 146, 1999-2049, https://doi.org/ 10.1002/QJ.3803.

Hoyer, S., and J. Hamman, 2017: xarray: N-D labeled arrays and datasets in Python. J. Open Res. Software, 5, 10, https://doi.org/ 10.5334/jors.148.

Hunter, J. D., 2007: Matplotlib: A 2D graphics environment. Comput. Sci. Eng., 9, 90-95, https://doi.org/10.1109/MCSE.2007.55.

Iwasaki, T., T. Shoji, and Y. Kanno, 2014: Isentropic analysis of polar cold airmass streams in the Northern Hemispheric winter. J. Atmos. Sci., 71, 2230-2243, https://doi.org/10.1175/ JAS-D-13-058.1. 
Jung, T., S. Serrar, and Q. Wang, 2014: The oceanic response to mesocale atmospheric forcing. Geophys. Res. Lett., 41, 12551260, https://doi.org/10.1002/2013GL059040.

Kolstad, E. W., 2006: A new climatology of favourable conditions for reverse-shear polar lows. Tellus, 58A, 344-354, https:// doi.org/10.1111/j.1600-0870.2006.00171.x.

- 2011: A global climatology of favourable conditions for polar lows. Quart. J. Roy. Meteor. Soc., 137, 1749-1761, https:// doi.org/10.1002/qj.888

- 2017: High ocean wind speed during marine cold air outbreaks. Quart. J. Roy. Meteor. Soc., 143, 2084-2092, https:// doi.org/10.1002/qj.3068.

— , and T. J. Bracegirdle, 2008: Marine cold-air outbreaks in the future: An assessment of IPCC AR4 model results for the Northern Hemisphere. Climate Dyn., 30, 871-885, https:// doi.org/10.1007/s00382-007-0331-0.

,$- \ldots$, and I. A. Seierstad, 2009: Marine cold-air outbreaks in the North Atlantic: Temporal distribution and associations with large-scale atmospheric circulation. Climate Dyn., 33, 187-197, https://doi.org/10.1007/s00382-008-0431-5.

Laffineur, T., C. Claud, J.-P. Chaboureau, and G. Noer, 2014: Polar lows over the Nordic seas: Improved representation in ERAInterim compared to ERA-40 and the impact on downscaled simulations. Mon. Wea. Rev., 142, 2271-2289, https://doi.org/ 10.1175/MWR-D-13-00171.1.

Landgren, O. A., Y. Batrak, J. E. Haugen, E. Stoylen, and T. Iversen, 2019a: Polar low variability and future projections for the Nordic and Barents Seas. Quart. J. Roy. Meteor. Soc., 145, 3116-3128, https://doi.org/10.1002/qj.3608.

— I. A. Seierstad, and T. Iversen, 2019b: Projected future changes in marine cold air outbreaks associated with polar lows in the North Atlantic Ocean. Climate Dyn., 53, 25732585, https://doi.org/10.1007/s00382-019-04642-2.

Liu, A., G. Moore, K. Tsuboki, and I. Renfrew, 2006: The effect of the sea-ice zone on the boundary-layer roll clouds during coldair outbreaks. Bound.-Layer Meteor., 118, 557-581, https:// doi.org/10.1007/s10546-005-6434-4.

May, R. M., S. C. Arms, P. Marsh, E. Bruning, J. R. Leeman, K. Goebbert, J. E. Thielen, and Z. S. Bruick, 2020: MetPy: A Python package for meteorological data. Accessed 25 June 2020, https://doi.org/10.5065/D6WW7G29..

McKinney, W., 2010: Data structures for statistical computing in Python. Proc. Ninth Python in Science Conf. (SciPy 2010), Austin, TX, 5661, https://doi.org/10.25080/Majora-92bf1922-00a.

Michel, C., A. Terpstra, and T. Spengler, 2018: Polar mesoscale cyclone climatology for the Nordic seas based on ERA-Interim. J. Climate, 31, 2511-2532, https://doi.org/10.1175/JCLI-D-16-0890.1.

Moore, G., and I. Renfrew, 2005: Tip jets and barrier winds: A QuikScat climatology of high wind speed events around Greenland. J. Climate, 18, 3713-3725, https://doi.org/10.1175/ JCLI3455.1.

,-- , and R. Pickart, 2012: Spatial distribution of air-sea heat fluxes over the sub-polar North Atlantic Ocean. Geophys. Res. Lett., 39, L18806, https://doi.org/10.1029/2012GL053097.

—, K. Vage, R. Pickart, and I. Renfrew, 2015: Decreasing intensity of open-ocean convection in the Greenland and Iceland Seas. Nat. Climate Change, 5, 877-882, https://doi.org/ 10.1038/nclimate2688.

Noer, G., Ø. Saetre, T. Lien, and Y. Gusdal, 2011: A climatological study of polar lows in the Nordic seas. Quart. J. Roy. Meteor. Soc., 137, 1762-1772, https://doi.org/10.1002/qj.846.

Oltmanns, M., F. Staneo, G. Moore, and S. Mernild, 2014: Strong downslope wind events in Ammassalik, southeast Greenland.
J. Climate, 27, 977-993, https://doi.org/10.1175/JCLI-D-1300067.1.

Pagowski, M., and G. Moore, 2001: A numerical study of an extreme cold-air outbreak over the Labrador Sea: Sea ice, airsea interaction, and development of polar lows. Mon. Wea. Rev., 129, 47-72, https://doi.org/10.1175/1520-0493(2001) $129<0047$ :ANSOAE $>2.0$. CO; 2 .

Papritz, L., 2017: Synoptic environments and characteristics of cold air outbreaks in the Irminger Sea. Int. J. Climatol., 37, 193-207, https://doi.org/10.1002/joc.4991.

— clones for the decay of cold air outbreaks: A numerical process study from the Pacific sector of the Southern Ocean. Mon. Wea. Rev., 144, 315-336, https://doi.org/10.1175/MWR-D-150268.1.

—_, and T. Spengler, 2017: A Lagrangian climatology of wintertime cold air outbreaks in the Irminger and Nordic seas and their role in shaping air-sea heat fluxes. J. Climate, 30, 27172737, https://doi.org/10.1175/JCLI-D-16-0605.1.

—- and H. Sodemann, 2018: Characterizing the local and intense water cycle during a cold air outbreak in the Nordic seas. Mon. Wea. Rev., 146, 3567-3588, https://doi.org/10.1175/MWR-D18-0172.1.

— S. Pfahl, H. Sodemann, and H. Wernli, 2015: A climatology of cold air outbreaks and their impact on air-sea heat fluxes in the high-latitude South Pacific. J. Climate, 28, 342-364, https:// doi.org/10.1175/JCLI-D-14-00482.1.

Pickart, R., M. Spall, M. Ribergaard, G. Moore, and R. Miliff, 2003: Deep convection in the Irminger Sea forced by the Greenland tip jet. Nature, 424, 152-156, https://doi.org/10.1038/nature01729.

Pithan, F., and Coauthors, 2018: Role of air-mass transformations in exchange between the Arctic and mid-latitudes. Nat. Geosci., 11, 805-812, https://doi.org/10.1038/s41561-018-0234-1.

Renfrew, I. A., and G. Moore, 1999: An extreme cold-air outbreak over the Labrador Sea: Roll vortices and air-sea interaction. Mon. Wea. Rev., 127, 2379-2394, https://doi.org/10.1175/15200493(1999)127<2379:AECAOO>2.0.CO;2.

— , and J. C. King, 2000: A simple model of the convective internal boundary layer and its application to surface heat flux estimates within polynyas. Bound.-Layer Meteor., 94, 335-356, https://doi.org/10.1023/A:1002492412097.

—, G. Petersen, D. Sproson, G. Moore, H. Adiwidjaja, S. Zhang, and R. North, 2009: A comparison of aircraft-based surfacelayer observations over Denmark Strait and the Irminger Sea with meteorological analysis and QuikScat winds. Quart. J. Roy. Meteor. Soc., 135, 2046-2066, https://doi.org/10.1002/qj.444.

_ Bull. Amer. Meteor. Soc., 100, 1795-1817, https://doi.org/ 10.1175/BAMS-D-18-0217.1.

_- and Coauthors, 2021: An evaluation of surface meteorology and fluxes over the Iceland and Greenland Seas in ERA5 reanalysis: The impact of sea ice distribution. Quart. J. Roy. Meteor. Soc., 147, 691-712, https://doi.org/10.1002/ QJ.3941.

Sergeev, D., 2018: Characteristics of polar lows in the Nordic seas and the impact of orography and sea ice on their development. Doctoral thesis, University of East Anglia, 138 pp.

—, I. Renfrew, T. Spengler, and S. Dorling, 2017: Structure of a shear-line polar low. Quart. J. Roy. Meteor. Soc., 143, 12-26, https://doi.org/10.1002/qj.2911.

,-- , and,- 2018 : Modification of polar low development by orography and sea ice. Mon. Wea. Rev., 146, 3325-3341, https://doi.org/10.1175/MWR-D-18-0086.1. 
Shapiro, M., L. Fedor, and T. Hampel, 1987: Research aircraft measurements of a polar low over the Norwegian Sea. Tellus, 39A, 272306, https://doi.org/10.1111/j.1600-0870.1987.tb00309.x.

Sproson, D. A., I. Renfrew, and K. J. Heywood, 2008: Atmospheric conditions associated with oceanic convection in the SouthEast Labrador Sea. Geophys. Res. Lett., 35, L06601, https:// doi.org/10.1029/2007GL032971.

Terpstra, A., and S. Watanabe, 2020: Polar lows. Oxford Research Encyclopedia of Climate Science, Oxford University Press, https://doi.org/10.1093/acrefore/9780190228620.013.775.

Våge, K., T. Spengler, H. C. Davies, and R. S. Pickart, 2009: Multievent analysis of the westerly Greenland tip jet based upon 45 winters in ERA-40. Quart. J. Roy. Meteor. Soc., 135, 19992011, https://doi.org/10.1002/qj.488.

Wacker, U., K. J. Potty, C. Lupkes, J. Hartmann, and M. Raschedorfer, 2005: A case study on a polar cold air outbreak over Fram Strait using a mesoscale weather prediction model. Bound.-Layer Meteor., 117, 301-336, https://doi.org/ 10.1007/s10546-005-2189-1.

Wagner, J., A. Gohm, A. Dörnbrack, and A. Schäfler, 2011: The mesoscale structure of a polar low: Airborne lidar measurements and simulations. Quart. J. Roy. Meteor. Soc., 137, 15161531, https://doi.org/10.1002/qj.857.

Watanabe, S., H. Niino, and W. Yanase, 2016: Climatology of polar mesocyclones over the Sea of Japan using a new objective tracking method. Mon. Wea. Rev., 144, 2503-2515, https:// doi.org/10.1175/MWR-D-15-0349.1.

- —_, and — 2017: Composite analysis of polar mesocyclone over the western part of the Sea of Japan. Mon. Wea. Rev., 147, 985-1004, https://doi.org/10.1175/MWR-D-17-0107.1.

Zappa, G., and L. Shaffrey, 2014: Can polar lows be objectively identified and tracked in the ECMWF operational analysis and the ERA-Interim reanalysis? Mon. Wea. Rev., 142, 25962608, https://doi.org/10.1175/MWR-D-14-00064.1. 